\title{
PARTICLE FLUXES ASSOCIATED WITH MESOSCALE EDDIES IN THE SARGASSO SEA
}

K.O. Buesseler*1, C. Lamborg ${ }^{1}$, P. Cai ${ }^{2}$, R. Escoube ${ }^{3,1}$, R. Johnson ${ }^{4}$, S. Pike ${ }^{1}$, P. Masque ${ }^{5}$, D. McGillicuddy ${ }^{1}$, and E. Verdeny ${ }^{5}$

*(Corresponding Author)

${ }^{1}$ Woods Hole Oceanographic Institution, 360 Woods Hole Road, MS 25, Woods Hole, MA 02543-1541, USA Phone: 508-289-2309; Fax: 508-457-2155; kbuesseler@whoi.edu

${ }^{2}$ State Key Laboratory of Marine Environmental Science, Xiamen University, Xiamen 361005 , CHINA

${ }^{3}$ University of Pierre et Marie Curie 4, place Jussieu 75252 Paris Cedex 05 FRANCE

${ }^{4}$ Bermuda Institute of Ocean Sciences (formerly BBSR), 17 Biological Lane, Ferry Reach, St. George's GE 01, BERMUDA

${ }^{5}$ Institut de Ciència i Tecnologia Ambientals - Departament de Física, Universitat Autònoma de Barcelona, 08193 Bellaterra, SPAIN

Revised for DSRII “Eddies Volume”. Version Sept. 25, 2007

\section{ABSTRACT}

We examined the impact of a cyclonic eddy and mode-water eddy on particle flux in the Sargasso Sea. The primary method used to quantify flux was based upon measurements of the natural radionuclide, ${ }^{234} \mathrm{Th}$, and these flux estimates were compared to results from sediment traps in both eddies, and a ${ }^{210} \mathrm{Po} /{ }^{210} \mathrm{~Pb}$ flux method in the mode-water eddy. Particulate organic carbon (POC) fluxes at $150 \mathrm{~m}$ ranged from 1 to $4 \mathrm{mmol} \mathrm{C} \mathrm{m} \mathrm{m}^{-1}$ and were comparable between methods, especially considering differences in integration times scales of each approach. Our main conclusion is that relative to summer mean conditions at the Bermuda Atlantic Time-series Study (BATS) site, eddy-driven changes in biogeochemistry did not enhance local POC fluxes during this later, more mature stage of the eddy life cycle ( $>6$ months old). The absence of an enhancement in POC flux puts a constraint on the timing of higher POC flux events, which are thought to have caused the local $\mathrm{O}_{2}$ minima below each eddy, and must have taken place $>2$ months prior to our arrival. The mode-water eddy did enhance preferentially diatom biomass in its center where we estimated a factor of 3 times higher biogenic Si flux than the BATS summer 
average. An unexpected finding in the highly depth resolved ${ }^{234} \mathrm{Th}$ data sets are narrow layers of particle export and remineralization within the eddy. In particular, a strong excess ${ }^{234} \mathrm{Th}$ signal is seen below the deep chlorophyll maxima which we attribute to remineralization of ${ }^{234} \mathrm{Th}$ bearing particles. At this depth below the euphotic zone, de novo particle production in the euphotic zone has stopped, yet particle remineralization continues via consumption of labile sinking material by bacteria and/or zooplankton. These data suggest that further study of processes in ocean layers is warranted not only within, but below the euphotic zone.

Keywords: oceanic eddies; particle flux; thorium-234

\section{INTRODUCTION}

Mesoscale eddies may play a potentially significant role in the biogeochemistry of the upper ocean (McGillicuddy et al., 1998, Oschlies and Garcon, 1998; Oschlies 2002; Williams and Follows, 2003). In particular, eddies can impact nutrient distributions and thus the rates of nutrient supply to the euphotic zone. If nutrient fluxes are enhanced, one would expect a stimulation of marine phytoplankton growth in oligotrophic systems, and as a consequence, enhanced export out of the upper ocean to balance the supply of incoming nutrients. However, this balance between production and export need not be reached for any given point in space and time, as the community response to nutrient inputs is complex, and there are often multiple limitations to growth and multiple loss terms each with a different response time. Most of the organic carbon and associated nutrients are lost from the upper ocean via the biological pump, which refers to a combination of processes including vertical settling of particulate organic matter (POM), physical mixing of dissolved organic carbon (DOC) into subsurface waters, as 
well as the active transport of $\mathrm{C}$ associated with surface feeding and vertically migrating zooplankton (Volk and Hoffert, 1985). A first order question in the EDDIES (EDdies Dynamics, Mixing, Export, and Species Composition) project and the focus of this manuscript is: to what extent do eddies impact the efficiency or workings of this biological pump?

The study area for EDDIES was the Sargasso Sea where prior studies have suggested important roles for eddies in the regional biogeochemistry and $\mathrm{C}$ balances of this oligotrophic region (Siegel et al., 1999). Annual new production appears greater than can be explained based upon deep winter mixing, and mesoscale eddies have been suggested to be important in stimulating significant new production (McGillicuddy and Robinson, 1997). A time-series 1-D budget of C at BATS revealed imbalances in the seasonal drawdown of inorganic $\mathrm{C}$ that is not reflected in $\mathrm{C}$ export (Michaels et al., 1994). Indeed, the mean export of carbon measured by sediment traps (Steinberg et al., 2001) amounts to only one quarter of the annual new production implied by geochemical tracer observations in the region (Jenkins and Goldman, 1985; Jenkins, 1988a,b). Mesoscale eddies introduce considerable variability into the local conditions at a fixed point, such as sampled at the Bermuda Atlantic Time-series (BATS) site (Doney, 1996).

In this work we study the impact of eddies on sinking particle fluxes. These fluxes are thought to be the major loss term with respect to upper ocean $\mathrm{C}$ and nutrient cycles at BATS and many other sites. In a prior study on this topic, Sweeney et al. (2003) found that during a 3 year period, 4 out of 6 high particle flux events at BATS occurred in association with the passage of eddies. However the export response was variable and the age or biogeochemical state of the eddy appeared to be significant. In essence, the lifecycle of an eddy was postulated to progress 
from a single, or multiple injections of nutrients, cycles of enhanced productivity, biomass buildup, followed later by enhanced export and then a subsequent decline in biomass and export during more mature stages of the eddy cycle. Eddies in this region have a life time of several months to a year or more and generally propagate from east to west at speeds of 3-5 $\mathrm{km}^{-1 a y}{ }^{-1}$ (Siegel et al., 1999). Depending upon what stage the eddy was in when it passed by BATS, the time-series observations at this fixed site would reveal a different response that would complicate the interpretation of the impact of eddies on local biogeochemistry and particle export (Sweeney et al., 2003).

In the EDDIES project, we set out to sample different stages of an eddy's lifecycle by measuring particle export on two repeat visits to the same eddy spaced about one month apart. We also examined particle export variability within the eddy, to look for center vs. edge effects and other processes that might impact variability in export on the sub-mesoscale. To obtain this high spatial and temporal resolution, we used ${ }^{234} \mathrm{Th}\left(\mathrm{T}_{1 / 2}=24.1 \mathrm{~d}\right)$ as a particle flux tracer to estimate POC export. A recent review of its application can be found in a series of papers resulting from a conference entitled: "Future Applications of ${ }^{234} \mathrm{Th}$ in Aquatic Ecosystems" (Benitez-Nelson and Moore, 2006). Also, on each cruise we deployed and measured particle flux using a pair of standard drifting sediment traps. In the 2005 field season, we also had a limited ${ }^{210} \mathrm{Po}\left(\mathrm{T}_{1 / 2}=\right.$ $138.4 \mathrm{~d})$ and ${ }^{210} \mathrm{~Pb}\left(\mathrm{~T}_{1 / 2}=22.3 \mathrm{yr}\right)$ sampling program, a daughter/parent radioisotope pair that, like ${ }^{234} \mathrm{Th} /{ }^{238} \mathrm{U}$, can be used to estimate particle fluxes (Cochran and Masqué, 2003; Verdeny et al., submitted, this volume). 
Our particle export results are put in context of the physical and geochemical setting and evolving biological community structure as measured by other EDDIES investigators. In light of our results, we address the extent to which enhanced nutrient supply is balanced by our estimates of POC export during these 4 cruises. We also study shallow remineralization using ${ }^{234} \mathrm{Th}$ and thus examine the vertical layering of production, export and remineralization and how these might be impacted by light, nutrient supply and other physical and biological properties that change within the eddy.

\section{SAMPLING AND METHODS}

\subsection{Research Cruises}

There are 3 major classes of eddies in this region with different physical attributes, and the EDDIES project sampled two of them intensively. In 2004, we sampled a cyclonic eddy (identified as $\mathrm{C} 1$ in EDDIES and in this paper) which is characterized by upward displacement of both the seasonal and main pycnocline, resulting in transport of nutrients into the euphotic zone via upwelling. Cyclones are manifested as a surface cold water anomaly, a decreased surface sea level anomaly (SLA) and exhibit counterclockwise rotation. In 2005, we sampled a mode-water eddy (identified as A4), which is characterized by a deepening of the main pycnocline but shoaling of the shallower isopycnals, thus resulting in enhanced nutrient supply to the euphotic zone as well. Mode-water eddies have a clockwise rotation and elevated SLA. An overview and primary results of the EDDIES project can be found in McGillicuddy et al. (2007). Eddies are discernable via satellite altimetry which allows for near real time tracking and adaptive sampling in a Lagrangian mode. 
Data presented in this paper were collected on four cruises on the $R V$ Weatherbird II and for convenience in this paper, we designated the $2004 \mathrm{C} 1$ cruises as E1 (WB0409, June 24-July 2) and E2 (WB0413, Aug. 2-11), and the 2005 A4 cruises as E3 (EB0506, July 6-15) and E4 (WB0508, Aug 18-25). Basic hydrographic, nutrient, biogeochemical and C system parameters were measured on the same CTD casts as ${ }^{234} \mathrm{Th}$, collected along a series of transects and at targeted stations on each cruise. The subset of CTD stations where ${ }^{234} \mathrm{Th}$ samples were collected are shown in Figures 1 a-d, where they are plotted for each cruise relative to SLA. CTD ID number, date/time and sampling locations are included in Table 1. The radionuclide results and other data used here are available at the Ocean Carbon Biogeochemistry data management web site: http://ocb.whoi.edu/eddies.html.

\subsection{Thorium-234}

We have recently improved our methods for the determination of total ${ }^{234} \mathrm{Th}$ on $4 \mathrm{~L}$ samples collected on standard CTD casts (Buesseler et al., 2001a; Benitez-Nelson et al., 2001a). Since the cruises were relatively short, our efforts were focused on collecting and processing as many samples as possible at sea, and then returning samples immediately to WHOI for determination of ${ }^{234} \mathrm{Th}$ activities via beta counting. For the ${ }^{234} \mathrm{Th}$ flux approach, it is vitally important to have a precise and accurate determination of total ${ }^{234} \mathrm{Th}$, particularly in areas where the disequilibrium, i.e. difference between ${ }^{234} \mathrm{Th}$ and ${ }^{238} \mathrm{U}$, is expected to be small, such as in the Sargasso Sea. We do this by: 1) measuring ${ }^{234} \mathrm{Th}$ via low background beta counting to a counting error that is generally $<2 \%$; 2) determining the background of other possible beta emitters by recounting each sample after 5-6 months, at which point ${ }^{234} \mathrm{Th}$ has decayed; and 3) using a ${ }^{230} \mathrm{Th}$ yield monitor to correct measured ${ }^{234} \mathrm{Th}$ activities for systematic and non-systematic inefficiencies in the isolation of Th from seawater (details in Pike et al., 2005). While on average ${ }^{234} \mathrm{Th}$ yields with this 
method are high (close to $95 \%$ in this study), there is an expected distribution of yields around the mean and a small number of "flyers" with systematically low yields (Figure 2). This distribution is larger than our counting error, and low yields would lower apparent ${ }^{234} \mathrm{Th}$ activities and bias fluxes too high. This illustrates the necessity of using a yield monitor in order to develop a data set of the highest quality. Thorium-234 data are decay corrected to the time of sampling, and errors are propagated from the initial and final measurement of ${ }^{234} \mathrm{Th}$, as well as the error on the ${ }^{230} \mathrm{Th}$ yield correction. This propagated error on total ${ }^{234} \mathrm{Th}$ averages $\pm 3-4 \%$ for the entire data set. Uranium-238 can be estimated from salinity, and in the open ocean this relationship is thought to hold within $\pm<1 \%$ (Chen et al., 1986) though differences between groups and settings can be larger ( $>3 \%$; Rutgers van der Loeff et al., 2006; Pates and Muir, 2007). Unpublished data from this lab suggests that the U-salinity relationship of Chen et al. (1986) fits Bermuda waters quite well. Five to ten deep water samples $(4000 \mathrm{~m})$ were analyzed on each cruise and these showed a ${ }^{234} \mathrm{Th} /{ }^{238} \mathrm{U}$ ratio of 0.992 , and a standard deviation of $3.8 \%$ $(\mathrm{n}=30)$.

We also present here ${ }^{234} \mathrm{Th}$ determined on size fractionated particulate samples collected via insitu pumps (sampling date and location in Table 2). We deployed up to 4 battery powered in-situ pumps at different depths to filter $200-400 \mathrm{~L}$ of seawater sequentially through a $53 \mu \mathrm{m}$ pore size screen followed by a $1 \mu \mathrm{m}$ nominal pore size quartz filter (both are $142 \mathrm{~mm}$ diameter). Details of this sampling method have been published elsewhere (Buesseler et al., 2001a). As with total ${ }^{234} \mathrm{Th}$ in seawater, particulate samples are beta counted for initial ${ }^{234} \mathrm{Th}$ activities and later for background corrections. Beta counting efficiencies for particulate samples are calibrated by complete sample digestion and radiochemical purification of selected samples using traditional 
methods (Rutgers van der Loeff et al., 2006). Thorium-234 samples from sediment traps (see 2.4.) are processed in the same way as the filtered particles.

\subsection{Polonium-210 and Lead-210}

Samples for ${ }^{210} \mathrm{Po}$ and ${ }^{210} \mathrm{~Pb}$ were collected from 15-16 different depths over the upper 400-500 $\mathrm{m}$ from four profiles during the E3 and E4 cruises. Three out of four profiles were collected inside the eddies, and one at the edge. The analytical methods followed were similar to Masqué et al. (2002). The samples were acidified, spiked with ${ }^{209} \mathrm{Po}\left(\mathrm{T}_{1 / 2}=102 \mathrm{y}\right)$ and stable $\mathrm{Pb}^{2+}$ yield tracers, and $\mathrm{Fe}^{3+}$ was added as a carrier. After 12 hours of equilibration, $\mathrm{pH}$ was adjusted to 8.5 with $\mathrm{NH}_{4} \mathrm{OH}$, and an Fe-precipitate $\left(\mathrm{Fe}(\mathrm{OH})_{3}\right)$ allowed to form and settle. The supernatant was carefully siphoned off and the precipitate transferred to $250 \mathrm{~mL}$ bottles. Radiochemical purification and measurement were conducted in the laboratory to determine final ${ }^{210} \mathrm{~Pb}$ and ${ }^{210} \mathrm{Po}$ activities after corrections for decay to the date of collection and procedural blanks. Chemical recoveries of both ${ }^{210} \mathrm{Po}$ and ${ }^{210} \mathrm{~Pb}$ ranged from 70 to $98 \%$. The $\mathrm{POC} /{ }^{210} \mathrm{Po}$ ratio was also determined in the $>53 \mu \mathrm{m}$ size particles collected via in-situ pumps at 120-150 m depth. Analyses of ${ }^{210} \mathrm{Po}$ on particles was made after complete digestion per previously published methods (Masqué et al., 2002).

\subsection{Sediment trap and filtered particle samples}

VERTEX style sediment traps (Knauer et al, 1979; Martin et al., 1987) were deployed during EDDIES to directly capture sinking particles for flux analyses (trap trajectories plotted as solid line on Figure 1 maps). For each of these floating arrays, multiple collection tubes (area $=$ $0.0039 \mathrm{~m}^{2}$ ) were used to collect passively sinking material over a deployment period of 3-6 days. At the end of each trap deployment, samples were processed according to standard BATS 
protocols. This involves carefully pouring off waters overlying the formalin poisoned brine found at the bottom of each collection tube, and manual removal in the lab using a microscope of zooplankton "swimmers" which are thought to enter the trap actively and die in the poison, vs. as associated with sinking debris. Each sampling tube is treated as a separate sample ( $\mathrm{n}=1-4$ tubes per elemental analysis) and analyzed individually for CHN or mass at BATS, or for ${ }^{234} \mathrm{Th}$ at WHOI. It has been previously shown that for ${ }^{234} \mathrm{Th}$, unlike POC and mass, the swimmer flux is insignificant, and thus we did not remove swimmers in the samples analyzed for ${ }^{234} \mathrm{Th}$ (Coale, 1990; Buesseler et al., 1994). Sample processing as well as analytical methods for POC, PIN and bSi have been reported in earlier studies (Buesseler et al., 2005).

\section{RESULTS}

\subsection{Vertical profiles of total ${ }^{234} \mathrm{Th}$ and ancillary data}

The vertical distributions of total ${ }^{234} \mathrm{Th}$ share some common features in both $\mathrm{C} 1$ and $\mathrm{A} 4$. In all of these profiles, ${ }^{234} \mathrm{Th}$ deficits (i.e. ${ }^{234} \mathrm{Th} /{ }^{238} \mathrm{U}<1$ ) are found down to depths just at or below the deep chlorophyll-a maximum (DCM), which lies directly above the nutricline at $100-150 \mathrm{~m}$ (Figure 3). The ${ }^{234} \mathrm{Th}$ deficit indicates that in the upper $100-150 \mathrm{~m}$ of the water column, the net rate of particle removal of ${ }^{234} \mathrm{Th}$ associated with the export of sinking particles is greater than its resupply via ingrowth from ${ }^{238} \mathrm{U}$. On average the total ${ }^{234} \mathrm{Th}$ activities in the upper $120 \mathrm{~m}$ during cruises E1, E2, E3, E4 are 2.34, 2.39, 2.44 and $2.33 \mathrm{dpm} \mathrm{L}^{-1}$ respectively though there is considerable station to station variability and depth structure in the ${ }^{234} \mathrm{Th}$ activity profiles on any given cruise (see below). These average ${ }^{234} \mathrm{Th}$ activities are the same within the error of an individual ${ }^{234} \mathrm{Th}$ measurement. Thorium-234 activities in this range relative to ${ }^{238} \mathrm{U}$ (average ${ }^{238} \mathrm{U}=2.59 \mathrm{dpm} \mathrm{L}{ }^{-1}$ ) indicate low particle export on sinking particles, similar to prior studies at 
BATS (Buesseler et al., 2000; Sweeney et al., 2003). This observation indicates that to first order, particle export in association with both eddies $\mathrm{C} 1$ and A4 is not exceptionally high. For example, mixed layer ${ }^{234} \mathrm{Th}$ activities as low as $1 \mathrm{dpm} \mathrm{L}^{-1}$ were found at the end of the North Atlantic spring bloom (Buesseler et al., 1992).

When profiles are examined on transects across the eddies, the data show physical and biogeochemical features characteristic of these two eddy types as described by McGillicuddy et al. (2007). Looking first at the cyclonic eddy C1 (Figure 4, left panels), these features include upward displacement of deep isopycnals in the center of the eddy and downwelling of surface waters, the latter postulated to be due to the impact of wind-eddy interactions in $\mathrm{C} 1$ (McGillicuddy et al., 2007). In the upper $150 \mathrm{~m}$ at $\mathrm{C} 1$, we see measurable submesocale variability in the vertical distributions of total ${ }^{234} \mathrm{Th}$ that does not appear to be associated with the eddy center or edge stations (Figure 4). There appear to be thin, $10-20 \mathrm{~m}$ lenses of low total ${ }^{234} \mathrm{Th}$ activity that are continuous between some stations, but are not found necessarily in association with the shallow $\mathrm{O}_{2}$ maxima at $50 \mathrm{~m}$, or the DCM, which in $\mathrm{C} 1$ is found preferentially at the edge stations. In C1, low chlorophyll-a, or low plankton biomass in the center of the eddy, is thought to be a result of local downwelling in the eddy center. There is certainly no direct correlation here between total ${ }^{234} \mathrm{Th}$ activity and chlorophyll biomass, and there are considerable submesoscale variations in many other parameters.

An unusual feature of $\mathrm{C} 1$ was the finding of low $\mathrm{O}_{2}$ associated with the core of the eddy feature centered broadly between 200-400m (Figure 4; sigma-t $=26.3-26.5 \mathrm{~kg} \mathrm{~m}^{-3}$ ). This eddy related feature has been attributed to remineralization of POC at depth, resulting from an earlier 
plankton bloom with significantly enhanced new and export production (McGillicuddy et al., 2007). In ${ }^{234} \mathrm{Th}$ studies, rapid remineralization or consumption of sinking particles carrying ${ }^{234} \mathrm{Th}$ to depth, results in "excess" ${ }^{234} \mathrm{Th}$ (i.e. ${ }^{234} \mathrm{Th} /{ }^{238} \mathrm{U}>1$ ) that is an indication of local remineralization maxima (e.g. Bacon et al., 1996). The fact that we do not see excess ${ }^{234} \mathrm{Th}$ at the depth of the $\mathrm{O}_{2}$ minimum and preferentially in these central stations suggests that the POC export event occurred more than several half lives prior to our arrival ( $>2$ months). Unlike ${ }^{234} \mathrm{Th}$, low $\mathrm{O}_{2}$ anomalies can be formed by an initial remineralization event, but only dissipated via mixing processes. Thorium-234 on the other hand, returns to secular equilibrium with ${ }^{238} \mathrm{U}$ after several half lives, and this disequilibrium can be observed depending upon the precision of our ${ }^{234} \mathrm{Th}$ analyses and the magnitude of the initial disequilibrium or excess (see Section 4.2).

In the mode-water eddy, A4, we also see significant submesoscale variability in total ${ }^{234} \mathrm{Th}$ in the upper $150 \mathrm{~m}$, with again thin, $10 \mathrm{~m}$ thick layers of lower ${ }^{234} \mathrm{Th}$ activity within the upper $50 \mathrm{~m}$ when contoured across single eddy transects (Figure 4, right panels). As A4 is a mode-water eddy, there is an upward displacement of the seasonal thermocline and depression of the main thermocline. In A4, the phytoplankton biomass was concentrated in a DCM at $100 \mathrm{~m}$ but only in the central stations, where chlorophyll-a concentrations were up to 8 standard deviations higher than the BATS mean (McGillicuddy et al., 2007). Microscopic cell counts and HPLC pigment data suggest peak chlorophyll concentrations in the DCM were associated with diatoms (McGillicuddy et al., 2007). Not seen in Figure 4 because it was found much deeper, between $700-1000 \mathrm{~m}$, is another strong $\mathrm{O}_{2}$ minimum anomaly localized in the A4 eddy center (McGillicuddy et al., 2007). Similar to $\mathrm{C} 1$, the lack of ${ }^{234} \mathrm{Th}$ excess in association with this 
feature (data not shown), points to an origin for the deep $\mathrm{O}_{2}$ minimum several months or more prior to our first cruise to A4 (see Section 4.2).

Since the depth of isopycnal surfaces are impacted by eddy dynamics, it is informative when comparing properties across several stations to consider vertical variability vs. density. When plotted in this way, the DCM aligns along a density of sigma- $\mathrm{t}=26.18 \mathrm{~kg} \mathrm{~m}^{-3}$ during $\mathrm{C} 1$ and $26.26 \mathrm{~kg} \mathrm{~m}^{-3}$ during A4 (Figure 5a \& 5b). The chlorophyll associated with the DCM is significantly enhanced in the central stations in A4 (filled symbols in Figure 5) but with edge stations in $\mathrm{C} 1$ (open symbols). Essentially, the depth of the DCM is set by the depth of minimal light needed for phytoplankton growth and the supply of nutrients from below, i.e. the upper boundary of the shallow nutricline as clearly seen at these same isopycnal surfaces.

A narrow layer of excess ${ }^{234} \mathrm{Th}$ immediately below the DCM becomes evident when plotted vs. density (Figure $5 \mathrm{a} \& 5 \mathrm{~b}$ ). This feature is centered around $150 \mathrm{~m}$ (sigma- $\mathrm{t}=26.2-26.5 \mathrm{~kg} \mathrm{~m}^{-3}$ for $\mathrm{C} 1$ and 26.3 for A4) at all stations and is thus shallower than the $\mathrm{O}_{2}$ minimum discussed previously. When compared to $\mathrm{C} 1$, the $\mathrm{A} 4$ excess ${ }^{234} \mathrm{Th}$ peak is also larger in magnitude and tighter in terms of its distribution vs. density. In both eddies, this peak in excess ${ }^{234} \mathrm{Th}$ is found at both central and other station locations (filled vs. open symbols in Figure 5). To explain this layer of excess ${ }^{234} \mathrm{Th}$ one must invoke rapid remineralization, particle break up, or at least a slowing down of sinking particles, to allow an excess of this isotope to build up relative to ${ }^{238} \mathrm{U}$. The evidence of a narrow layer of shallow remineralization in EDDIES is better resolved than in prior studies (see Section 4.4). 
Most, but not all, ${ }^{234} \mathrm{Th}$ profiles also showed secondary ${ }^{234} \mathrm{Th}$ minima centered around $300 \mathrm{~m}$ (Figures 3 \& 4). This was found to a greater degree on E1, E2 and E4 than during E3, and with no obvious correlation between this feature and eddy center or edge stations. Our depth resolution is not nearly as high below $150 \mathrm{~m}$ vs. above, but the frequent finding of a deep minimum in ${ }^{234} \mathrm{Th} /{ }^{238} \mathrm{U}$ at $300 \mathrm{~m}$ suggests deeper particle repackaging and export. This has been commented on in only a few prior studies (such as Benitez-Nelson et al., 2001b; Usbeck et al., 2002), but may have been missed in other programs where there is lower vertical resolution sampling and also an emphasis on shallow sampling only. If in steady state, a fraction of the slowly sinking particles must be being converted into more rapidly sinking material at that depth (see 4.4).

\subsection{Fluxes of thorium-234 and POC}

We can model the export of ${ }^{234} \mathrm{Th}$ on sinking particles by comparing the activity balance of total ${ }^{234} \mathrm{Th}$ to known sources and sinks, which is mathematically expressed as:

$$
\partial^{234} \mathrm{Th} / \partial \mathrm{t}=\left({ }^{238} \mathrm{U}-{ }^{234} \mathrm{Th}\right) \cdot \lambda-\mathrm{P}+\mathrm{V}
$$

where $\partial \mathrm{Th} / \partial \mathrm{t}$ is the change in ${ }^{234} \mathrm{Th}$ activity with time, ${ }^{238} \mathrm{U}$ is the uranium activity determined from salinity $\left({ }^{238} \mathrm{U}\left(\mathrm{dpm} \mathrm{L}{ }^{-1}\right)=0.0703 *\right.$ Salinity; Chen et al., 1986), ${ }^{234} \mathrm{Th}$ is the measured activity of total ${ }^{234} \mathrm{Th}, \lambda$ is the decay constant for ${ }^{234} \mathrm{Th}\left(=0.0288\right.$ day $\left.^{-1}\right), \mathrm{P}$ is the net export flux of ${ }^{234} \mathrm{Th}$ on sinking particles, and $\mathrm{V}$ is the sum of advective and diffusive ${ }^{234} \mathrm{Th}$ fluxes. When the ${ }^{234} \mathrm{Th}$ activity balance is integrated from the surface to a given depth, net export, $\mathrm{P}$, can be calculated on a dpm m $\mathrm{m}^{-2} \mathrm{~d}^{-1}$ basis at that depth. It should be noted that in some regions of the water column, biological remineralization of sinking particulate material results in a release of

${ }^{234} \mathrm{Th}$ from particles to a large enough extent to exceed secular equilibrium with ${ }^{238} \mathrm{U}$, i.e. and 
excess ${ }^{234} \mathrm{Th}$ signal. For a given layer, this effectively represents a negative flux, where the flux of ${ }^{234} \mathrm{Th}$ entering the top of the layer is larger than the flux leaving it. A recent review by Savoye et al. (2006) examines the assumptions behind this ${ }^{234} \mathrm{Th}$ flux model.

Because of arguments below about the lack of significant temporal variability or physical transport for ${ }^{234} \mathrm{Th}$, we use a 1-D steady state model to determine ${ }^{234} \mathrm{Th}$ flux associated with sinking particles. Using this model, we can calculate for each station the net flux of ${ }^{234} \mathrm{Th}$ vs. depth. Examples of representative flux profiles are shown in Figure 6 for $\mathrm{C} 1$ (left panel) and A4 (right panel) calculated for the same central eddy stations for which ${ }^{234} \mathrm{Th}$ activity data are plotted in Figure 3. Essentially, the ${ }^{234} \mathrm{Th}$ flux increases with depth at each of these stations until the depth at which total ${ }^{234} \mathrm{Th}$ equals or exceeds ${ }^{238} \mathrm{U}$ activities. If ${ }^{234} \mathrm{Th}={ }^{238} \mathrm{U}$ in a given depth interval, then the ${ }^{234} \mathrm{Th}$ flux through that region remains constant (for example between 120200m, E2 CTD8). If ${ }^{234} \mathrm{Th}>{ }^{238} \mathrm{U}$, indicating particle remineralization, the calculated ${ }^{234} \mathrm{Th}$ flux decreases (for example between 150-300m, E3 CTD18). We will focus our attention on the flux at $150 \mathrm{~m}$, since during all 4 cruises this depth is below the euphotic zone and DCM and it is coincident with the depth of sediment traps deployed during eddies. Results for ${ }^{234} \mathrm{Th}$ flux at $150 \mathrm{~m}$ calculated in this manner for each station are provided in Table 1.

It is useful to briefly review the possible errors introduced by using a 1-D steady-state model in this setting. The advantage of using ${ }^{234} \mathrm{Th}$ as a particle flux tracer compared to measuring timeseries budgets of stable elements, such as $\mathrm{C}$ or nutrients, is that the net flux term, $\mathrm{P}$, calculated from equation 1 , is in most cases tightly constrained by the difference between total ${ }^{234} \mathrm{Th}$ production and decay rates $\left(\left({ }^{238} \mathrm{U}-{ }^{234} \mathrm{Th}\right) \cdot \lambda\right)$, and not the two other terms in equation 1 
$\left(\partial^{234} \mathrm{Th} / \partial \mathrm{t}\right.$ and $\left.\mathrm{V}\right)$. Since we have time-series data collected in a Lagrangian manner we can look for changes in total ${ }^{234} \mathrm{Th}$ vs. time directly, similar to $\mathrm{SF}_{6}$ tagged iron fertilization experiments (Buesseler et al., 2005). However, as discussed earlier (Section 3.1), in both C1 and A4, there is no significant trend with time in the average ${ }^{234} \mathrm{Th}$ activities when integrated over the upper 120 or $150 \mathrm{~m}$, thus we ignore $\partial^{234} \mathrm{Th} / \partial \mathrm{t}$ and use a steady state model in this study. This does add a small uncertainty to our final flux predictions. Given total errors on ${ }^{234} \mathrm{Th}$ of $3-4 \%$, we cannot reliably detect a ${ }^{234}$ Th flux at $150 \mathrm{~m}$ that is less than about $300-400 \mathrm{dpm} \mathrm{m}^{-2} \mathrm{~d}^{-1}$.

In addition to the assumption of steady state, we also assume that physical transport via advection and diffusion is negligible, i.e. $\mathrm{V}=0$ in equation 1 . By combining our measurements of horizontal and physical gradients in total ${ }^{234} \mathrm{Th}$ activity with the physical mixing information obtained by Jim Ledwell and colleagues during EDDIES (Ledwell et al., submitted, this volume), we can place first order estimates on the magnitude of $\mathrm{V}$. We consider three potential mechanisms contributing to V: horizontal and vertical submesoscale "eddy" diffusivity as well as vertical, isopycnal upwelling of water. Horizontal contributions are difficult to estimate quantitatively, but since no significant gradients in ${ }^{234} \mathrm{Th}$ deficit are seen across the eddy boundaries, we assume that horizontal diffusion within the eddy results in no net effect on ${ }^{234} \mathrm{Th}$ flux in vs. out of the eddy.

Ledwell et al. (submitted, this volume) injected a conservative tracer $\left(\mathrm{SF}_{6}\right)$ at a density of sigma-t $=26.26 \mathrm{~kg} \mathrm{~m}^{-3}$ during A4 as part of EDDIES, and from its vertical displacement and spreading, they calculated a vertical diffusivity of $0.35 \times 10^{-4} \mathrm{~m}^{2} \mathrm{~s}^{-1}\left(3.15 \mathrm{~m}^{2} \mathrm{~d}^{-1}\right)$ for this eddy. Using this value along with a maximum gradient in ${ }^{234} \mathrm{Th}$ activity of $0.4 \mathrm{dpm} \mathrm{L}^{-1}$ over half the depth of the 
region of ${ }^{234} \mathrm{Th}$ deficit (approximately $75 \mathrm{~m}$; Figure 5), one can calculate a vertical diffusive flux on the order of $14 \mathrm{dpm} \mathrm{m}^{-2} \mathrm{~d}^{-1}$. For vertical isopycnal advection of ${ }^{234} \mathrm{Th}$, we use Ledwell and colleagues' estimate of an upward vertical velocity of $0.55 \mathrm{~m} \mathrm{~d}^{-1}$ measured at the DCM. While this upward velocity would carry ${ }^{234} \mathrm{Th}$ into the upper $150 \mathrm{~m}$, the net impact on the $0-150 \mathrm{~m}{ }^{234} \mathrm{Th}$ activity balance is still minimal due to the relatively small activity gradient. During A4, the magnitude of this flux would be equivalent to about $125 \mathrm{dpm} \mathrm{m}^{-2} \mathrm{~d}^{-1}$. Thus, the vertical diapycnal and isopycnal fluxes of ${ }^{234} \mathrm{Th}$ are equivalent to 3 and $19 \%$ of the total sinking flux, respectively. Our 1-D steady state fluxes might systematically underestimate ${ }^{234} \mathrm{Th}$ by these amounts, but we feel that this is too small to consider when compared to other errors associated with the ${ }^{234} \mathrm{Th}$ flux model (Table 1).

Once we have an estimate of ${ }^{234} \mathrm{Th}$ flux on sinking particles, we can use it to predict the flux of other important constituents. We have pioneered the use of ${ }^{234} \mathrm{Th}$ as an elemental particle flux proxy, by simply multiplying ${ }^{234} \mathrm{Th}$ export on sinking particles by the element ${ }^{234} \mathrm{Th}$ ratio measured on the same sinking particles, i.e. for POC, flux POC $=$ flux ${ }^{234} \mathrm{Th} \times \mathrm{POC} /{ }^{234} \mathrm{Th}$ (Buesseler et al., 1992). This is an empirical approach that has inherent strengths and limitations that have been recently reviewed in some detail by Buesseler et al. (2006). Briefly, variations in $\mathrm{POC} /{ }^{234} \mathrm{Th}$ can result from a variety of geochemical and biological processes, such as particle aggregation/disaggregation, changes to surface:volume ratios (i.e. size/shape), decay of ${ }^{234} \mathrm{Th}$ (Cai et al., 2006), generation or consumption of complexing dissolved organic matter, shifts in particle type (i.e. surface binding characteristics) and preferential consumption of POC on sinking particles (i.e. lower POC/ ${ }^{234} \mathrm{Th}$ with depth). 
Without being able to predict $\mathrm{POC} /{ }^{234} \mathrm{Th}$ from first principles, sampling methods are of particular concern, since the approach relies on quantifying accurately the ratio between ${ }^{234} \mathrm{Th}$ and POC on sinking particles. If there are particles that dominate POC export that we miss with our sampling methods and these particles have a different $\mathrm{POC} /{ }^{234} \mathrm{Th}$ ratio, we may be over/under estimating the true POC flux. Similarly, we need site and depth specific POC ${ }^{234}$ Th data collected over the same time-scale as the integration time of our tracer. In this case, since we have both depth and time-series data for particulate ${ }^{234} \mathrm{Th}$ over the course of both pairs of cruises, we have an ideal match between the time scale of modeling ${ }^{234} \mathrm{Th}$ flux and the $\mathrm{POC} /{ }^{234} \mathrm{Th}$ associated with that flux. We also have samples from size fractionated material collected on filters and from sediment traps at a single depth $(150 \mathrm{~m})$. Confidence can be gained by comparing $\mathrm{POC} /{ }^{234} \mathrm{Th}$ collected by these different methods.

In Figure 7, $\mathrm{POC} /{ }^{234} \mathrm{Th}$ ratios are plotted for each of our cruises for the $>53 \mu \mathrm{m}$ fraction collected via in-situ pumping at 120 and $150 \mathrm{~m}$ from as many as 9 different pump casts for each cruise. Complete profiles (data not shown, can be found at the OCB data site) show that similar to other studies, $\mathrm{POC} /{ }^{234} \mathrm{Th}$ generally decreases with depth, though there can be considerable variability in this ratio in surface waters. However, we only apply this POC flux conversion at $150 \mathrm{~m}$, and are fortunate that by depths $>100 \mathrm{~m}$ there is considerably less $\mathrm{POC} /{ }^{234} \mathrm{Th}$ variability between stations and even between cruises (Figure 7). If a pair-wise comparison of the $\mathrm{POC} /{ }^{234} \mathrm{Th}$ ratios at 120 and $150 \mathrm{~m}$ is made, only the E4 samples show a difference that is statistically different at the $95 \%$ confidence level. In the case of E4, though, the 120 and 150 m values bracket the sediment trap POC ${ }^{234} \mathrm{Th}$ values. With few samples and little significant difference vs. time or depth, we propose that a more reliable approach is to average all of these 120 and $150 \mathrm{~m}$ data for 
a given cruise and apply that single ratio to the ${ }^{234} \mathrm{Th}$ flux at $150 \mathrm{~m}$ to derive POC export at that depth. We propagate the additional uncertainty introduced by variability in $\mathrm{POC} /{ }^{234} \mathrm{Th}$ into the POC flux calculations ( $\mathrm{POC})^{234} \mathrm{Th}$ ratios and POC fluxes in Table 1). These POC ${ }^{234} \mathrm{Th}$ ratios at depth are similar to other oligotrophic settings where similar filtration methods were used (e.g. Buesseler et al., 1995; Hung et al., 2004), though lower than some high latitude sites and during plankton blooms (e.g. Cochran et al., 2000; Amiel et al., 2002).

The ${ }^{234}$ Th-derived POC fluxes are plotted vs. CTD \# (Figure 8) and when we examine the flux data vs. CTD\# or location within the eddy (central stations are filled symbols; Table 1), we see no systematic trends that suggest either temporal changes in POC flux during a given cruise or variability associated with eddy center vs. edge stations. Using this approach, we feel we have a very robust determination of average $150 \mathrm{~m}$ POC flux from each of our cruises, which is equivalent to $4.3 \pm 1.5,1.7 \pm 0.6,1.4 \pm 0.8,1.4 \pm 0.6, \mathrm{mmol} \mathrm{C} \mathrm{m}^{-2} \mathrm{~d}^{-1}$ for E1, E2, E3, E4, respectively.

A primary assumption behind the ${ }^{234} \mathrm{Th}$ approach for estimating POC flux, is that the large particles collected on the $53 \mu \mathrm{m}$ screens are representative of the flux weighted particles that are actually carrying POC to depth. We can test this assumption directly by comparing the $150 \mathrm{~m}$ trap samples ( $\mathrm{n}=2$ per cruise) to the $>53 \mu \mathrm{m}$ particles collected by in situ pump at $150 \mathrm{~m}$ (gray symbols, Figure 7). In each case, there is a close similarity between the $\mathrm{POC} /{ }^{234} \mathrm{Th}$ ratios of these two sample types except for E2, where the average pump data are 2x lower than the pair of trap samples. There can be issues with accurate determination of POC and ${ }^{234} \mathrm{Th}$ in traps, so we cannot necessarily conclude that either value is "better" (see Section 3.3.), but the small 
difference between these $>53 \mu \mathrm{m}$ particles and traps places a narrow constraint on the variability in $\mathrm{POC} /{ }^{234} \mathrm{Th}$, and hence is one estimate of the overall accuracy of this approach.

\subsection{Sediment trap fluxes of ${ }^{234} \mathrm{Th}$, POC and mass}

During C1 cruises (E1 and E2), shallow drifting sediment traps were deployed either in a central eddy location (IN) or outside of the eddy feature (OUT; trap trajectories in Figure 1). On the E1 cruise "OUT" was defined by hydrographic and SLA anomalies. Since it is difficult to define a true OUT control, due in part to possible eddy/eddy interactions, the regular BATS sampling site was used as the OUT control during E2 (BATS cruise \#190). The bottom line is that on both E1 and E2, we did not see significant variability in the IN vs. OUT trap samples for ${ }^{234} \mathrm{Th}$, POC or mass flux (Figure 9). These $\mathrm{C} 1$ trap fluxes averaged $506 \pm 86 \mathrm{dpm} \mathrm{m}^{-2} \mathrm{~d}^{-1}, 1.7 \pm 0.6 \mathrm{mmol} \mathrm{C} \mathrm{m}^{-2}$ $\mathrm{d}^{-1}$ and $68 \pm 21 \mathrm{mg} \mathrm{m}^{-2} \mathrm{~d}^{-1}$ for ${ }^{234} \mathrm{Th}$, POC and mass for both traps on both cruises.

For A4 (E3 and E4), rather than attempt any OUT trap deployments, two pairs of traps were deployed at the same time, both within the center of the eddies feature. These traps remained within the eddy center (Figure 1) and are considered to be replicate flux estimates, thus providing some indication of within eddy variability in flux. While there is some tube to tube variability, the fluxes of ${ }^{234} \mathrm{Th}$, POC and mass are similar and show no trend vs. time (E3 vs. E4; Figure 9). These A4 trap fluxes averaged $473 \pm 148 \mathrm{dpm} \mathrm{m}^{-2} \mathrm{~d}^{-1}, 1.2 \pm 0.2 \mathrm{mmol} \mathrm{C} \mathrm{m}^{-2} \mathrm{~d}^{-1}$ and $67 \pm 12 \mathrm{mg} \mathrm{m}^{-2}$ $\mathrm{d}^{-1}$ for ${ }^{234} \mathrm{Th}$, POC and mass, respectively, for both cruises. The magnitude of these fluxes is also comparable to the summertime BATS average (average for June, July and August of 1989-2005: $2.1 \pm 0.7 \mathrm{mmol} \mathrm{C} \mathrm{m} \mathrm{m}^{-2} \mathrm{~d}^{-1}$ and $100 \pm 40 \mathrm{mg}$ total mass $\mathrm{m}^{-2} \mathrm{~d}^{-1}$; data available at BATS website). 
It should be noted that while we measure significant tube to tube variability for any given parameter, this is common in the BATS and other similar trap records and is thought to be due to the random and rare nature of sinking particles caught during short deployments using small diameter trap tubes. The ratios of $\mathrm{POC} /{ }^{234} \mathrm{Th}$ from traps discussed earlier in this paper are derived from the average of several tubes analyzed for any given deployment, and thus variability between tubes introduces additional uncertainty in the true composition and relative flux ratios of POC and ${ }^{234} \mathrm{Th}$ determined in separate tubes. An additional uncertainty in the trap derived $\mathrm{POC} /{ }^{234} \mathrm{Th}$ ratio is that zooplankton swimmers have extremely high $\mathrm{POC} /{ }^{234} \mathrm{Th}$ ratios (high $\mathrm{C}$ volume, lower surface area for ${ }^{234} \mathrm{Th}$ binding). While swimmers have a low ${ }^{234} \mathrm{Th}$ content, a few missed swimmers left in a POC sample can have a significant positive bias on the apparent POC/ ${ }^{234} \mathrm{Th}$ ratio (Rodriguez Y Baena et al., 2007).

There is also the possibility of hydrodynamic sorting when using traps, based upon biases in the collection of slow vs. fast sinking particles (Gardner, 2000; Buesseler et al., 2007a). In one prior study, differences of a factor of two higher POC/ ${ }^{234} \mathrm{Th}$ in standard BATS traps vs. traps designed to minimize hydrodynamic flow, have been attributed to this effect (Buesseler et al., 2000; Stanley et al., 2004). To look at trap collection efficiency, we can compare the magnitude of the ${ }^{234} \mathrm{Th}$ flux estimated from the water column data to the measured trap flux of ${ }^{234} \mathrm{Th}$. This calibration approach has been used to argue that there can be biases in trap collection efficiency due to hydrodynamic effects associated with collecting particles that are moving 1-2 orders of magnitude faster in the horizontal than vertical direction. Here, the ratio of ${ }^{234} \mathrm{Th}$ fluxes measured in the sediment traps versus calculated from the water-column observations are $40 \%$, $61 \%, 77 \%, 91 \%$ for E1, E2, E3, E4, respectively, thus significantly poorer in C1 than A4 in 
terms of absolute ${ }^{234} \mathrm{Th}$ fluxes. This finding of a lower than expected collection efficiency, especially for $\mathrm{C} 1$, is similar to other results where seasonal or annual comparisons with shallow traps have been made (Buesseler et al., 2007a), though both positive and negative deviations have been found in individual short term studies.

The bottom line is that there are uncertainties in the use of standard sediment traps to collect sinking particles, as well as whether filters can be used to collect material representative of sinking material based upon size. We are encouraged here by the minimal difference between either sampling method. Though we don't use the smaller diameter particles caught on the $>1$ $\mu \mathrm{m}$ quartz filter to characterize the $\mathrm{POC}{ }^{234} \mathrm{Th}$ ratio of sinking particles (since these small particles are assumed to settle more slowly), we note that the measured $\mathrm{POC} /{ }^{234} \mathrm{Th}$ ratio on this filter is only $25-50 \%$ lower than found on the $>53 \mu \mathrm{m}$ filter (data not shown). The reduced variability in $\mathrm{POC} /{ }^{234} \mathrm{Th}$ at depth and between methods, stations and cruises, makes our estimates of POC flux more likely to be representative of average conditions.

\subsection{Fluxes during $\mathrm{A} 4$ using ${ }^{210} \mathrm{Po} /{ }^{210} \mathrm{~Pb}$}

${ }^{210} \mathrm{~Pb}$ and ${ }^{210} \mathrm{Po}$ are both particle-reactive, with varying affinities both in terms of efficiency and type of matter to which they associate and, indeed, different binding mechanisms: ${ }^{210} \mathrm{~Pb}$ and ${ }^{210} \mathrm{Po}$ adsorb on particle surfaces, but ${ }^{210} \mathrm{Po}$ is also incorporated via biological activity and is preferentially enriched in organic tissue (Fisher et al., 1983; Kharkar et al., 1976; Shannon et al., 1970; Stewart and Fisher, 2003a\&b; Stewart et al., 2005). As a consequence, ${ }^{210}$ Po is more efficiently removed from surface waters than ${ }^{210} \mathrm{~Pb}$ via sinking particles, and results in disequilibrium between the two radionuclides throughout the upper 500m (Figure 10). This 
radionuclide pair has been proposed as a proxy for estimating POC export from the upper water column in a similar fashion as is done with the ${ }^{234} \mathrm{Th} /{ }^{238} \mathrm{U}$ pair (e.g. Stewart et al., 2007; Verdeny et al., submitted, this volume). Unlike the ${ }^{234} \mathrm{Th} /{ }^{238} \mathrm{U}$ pair, the ${ }^{210} \mathrm{Po} /{ }^{210} \mathrm{~Pb}$ pair appears to be in persistent disequilibrium throughout the top $500 \mathrm{~m}$ in the A4 eddy. This is consistent with measurements made at BATS by Kim and Church (2001), who found ${ }^{210} \mathrm{Po} /{ }^{210} \mathrm{~Pb}$ activity ratios generally below 0.5 except at very deep depths. This is not always the case, and in other studies ${ }^{210}$ Po data show shallower depletions more similar to ${ }^{234} \mathrm{Th}$ (e.g., Bacon et al., 1976).

Similar to ${ }^{234} \mathrm{Th}$ and equation 1 , the ${ }^{210} \mathrm{Po} /{ }^{210} \mathrm{~Pb}$ pair can be used to calculate the flux of ${ }^{210} \mathrm{Po}$ associated with sinking particles (Bacon et al., 1976), using $\lambda_{\text {Po }}$ for the decay constant for ${ }^{210} \mathrm{Po}$. We also used a steady-state model and average activities of total ${ }^{210} \mathrm{~Pb}$ and ${ }^{210} \mathrm{Po}$ in the upper $150 \mathrm{~m}$ to determine the fluxes of ${ }^{210} \mathrm{Po}$ at $150 \mathrm{~m}$ which ranged from 80 to $90 \mathrm{dpm} \mathrm{m}^{-2} \mathrm{~d}^{-1}$ for E3 and from 40 to $60 \mathrm{dpm} \mathrm{m}^{-2} \mathrm{~d}^{-1}$ for E4 (Table 3). For E3 the POC/ ${ }^{210}$ Po ratio in the $>53 \mu \mathrm{m}$ size particles ranged from 40 to $60 \mu \mathrm{mol} \mathrm{dpm}^{-1}$, and from 25 to $89 \mu \mathrm{mol} \mathrm{dpm}{ }^{-1}$ for $\mathrm{E} 4$ (no ${ }^{210}$ Po data are available from the traps). Again, analogous to ${ }^{234} \mathrm{Th}$, these ratios allow us to estimate a POC export flux at $150 \mathrm{~m}$ of 3.5-4.5 mmol C m $\mathrm{m}^{-2}$ for $\mathrm{E} 3$ and about a factor of two lower for E4 (1.5-3.3 mmol C m$\left.{ }^{-2} \mathrm{~d}^{-1}\right)$.

\section{DISCUSSION}

\subsection{Comparison of POC fluxes between methods and with BATS}

These ${ }^{234} \mathrm{Th}$ data were collected with an exceedingly high horizontal and vertical resolution relative to prior applications of this tracer. This allows us to examine particle export signatures on the submesocale within the eddy, and make reliable comparisons of average conditions within the eddy to control stations and the nearby BATS time-series site. Looking first at eddy averages 
and comparisons to the BATS summer time fluxes, we see little evidence with either ${ }^{234} \mathrm{Th},{ }^{210} \mathrm{Po}$ or the sediment trap data, that particle export is significantly enhanced in the eddies- at least within our ability to quantify export with these methods (Figure 11). Average POC fluxes using any of these methods range from 1 to $4 \mathrm{mmol} \mathrm{C} \mathrm{m}^{-2} \mathrm{~d}^{-1}$, and are generally within the range found in BATS climatology (June, July, August 1989-2005 POC trap flux at $150 \mathrm{~m}=2.1 \pm 0.7 \mathrm{mmol} \mathrm{C}$ $\mathrm{m}^{-2} \mathrm{~d}^{-1}$; more recent years, 2004-2005, are slightly lower $=1.6 \pm 0.5 \mathrm{mmol} \mathrm{C} \mathrm{m}^{-2} \mathrm{~d}^{-1}$; horizontal lines in Figure 11). These low fluxes are similar to other oligotrophic sites, such as the Hawaii Ocean Time-series, where both ${ }^{234} \mathrm{Th}$-based and traditional trapping studies have been used to determine POC export (Karl et al., 1996, Benitez-Nelson et al., 2001b). Note also that average POC fluxes derived from ${ }^{234} \mathrm{Th}$ are shown using either the $\mathrm{POC} /{ }^{234} \mathrm{Th}$ ratio from our pumps (light gray open bar) or traps (light gray hashed bar). Within errors, all of these ${ }^{234} \mathrm{Th}$-derived fluxes are the same for any given cruise, except for E2 when the trap had almost a factor of two higher POC $/^{234}$ Th (see Section 3.2.).

When comparing these flux estimates, it is important to note that each POC flux method averages over different time scales of flux. The trap deployments were shortest, collecting sinking particles over 3-6 days. Thorium-234 activities reflect flux conditions averaged over several weeks to month time scales, due to its 24 day half life. In $\mathrm{C} 1$, the ${ }^{234} \mathrm{Th}$-derived POC fluxes are higher than the traps, but this is also the cruise where we have some concern that the trap collection efficiencies were low, when comparing ${ }^{234} \mathrm{Th}$ measured trap fluxes to the calculated flux (see Section 3.3). So it is difficult to conclude whether or not the lower trap fluxes represent a recent decrease in particle export or low collection efficiency. At most, this 
POC flux difference is a factor of 2-3 for E1, and up to a factor of two for E2, but then only compared to the highest of the two ${ }^{234} \mathrm{Th}$ based E2 POC flux estimates.

For A4, the agreement between the ${ }^{234} \mathrm{Th}$-derived POC flux and traps is much better. Remember also that the comparison between trap and predicted ${ }^{234} \mathrm{Th}$ fluxes was quite good for both E3 and E4. The outlier for A4 POC flux are the ${ }^{210} \mathrm{Po}$-derived flux estimates (for 3 of 4 profiles), and this tracer integrates flux over the longest time scales- several months to a half year $\left(\mathrm{T}_{1 / 2}=138\right.$ d). So higher ${ }^{210} \mathrm{Po}$-derived POC fluxes might indicate earlier high flux events that were a factor of 2-3 larger than our summer observations. However, one caveat when applying the ${ }^{210} \mathrm{Po}$ flux gauge is that we are using the summer time $\mathrm{POC} /{ }^{210} \mathrm{Po}$ data from our filters, to extrapolate from summer ${ }^{210} \mathrm{Po}$ flux to POC export much earlier in the year. Since ${ }^{210}$ Po represents conditions over longer time scales, we would need samples of $\mathrm{POC} /{ }^{210} \mathrm{Po}$ during these earlier flux conditions to better constrain POC flux with this tracer. Also, the scavenging history of the parent radionuclide, ${ }^{210} \mathrm{~Pb}$, can impact the ${ }^{210} \mathrm{~Pb}:{ }^{210} \mathrm{Po}$ disequilibrium, and hence impact ${ }^{210} \mathrm{Po}$ derived fluxes.

\subsection{Comparisons of the Eddy Localized Oxygen Minima and POC Fluxes}

A major conclusion in McGillicuddy et al. (2007) is that the $\mathrm{O}_{2}$ minimum found in the central eddy stations at $\mathrm{C} 1(200-400 \mathrm{~m})$ and $\mathrm{A} 4(800-1000 \mathrm{~m})$, is a consequence of high particle export from eddy induced blooms that took place prior to our sampling. The implied magnitudes are one to three times annual new production. A major conclusion here is that POC fluxes measured during our occupations of the eddies were much smaller and not significantly elevated over BATS summer averages. This puts a time constraint on the high export event, since it must have been large enough to produce the $\mathrm{O}_{2}$ anomaly, but earlier in the eddy life cycle so that the signal 
in the ${ }^{234} \mathrm{Th}$ and ${ }^{210} \mathrm{Po}$ tracer field would have decayed away by the time of our observations of the more mature stages of eddies $\mathrm{C} 1$ and $\mathrm{A} 4$. Such a conclusion is consistent with the findings of Mouriño-Carballido and McGillicuddy (2006) who suggested net community production (and presumably POC export) decrease during the life cycle of an eddy, and may even shift from net autotrophy to net heterotrophy.

There are a couple of ways to scale past and current export events relative to the oxygen anomaly. First, using photosynthetic stoichiometry and measured $\mathrm{O}_{2}$ depletion between 200$400 \mathrm{~m}$, McGillicuddy et al. (2007) estimate the $\mathrm{C} 1$ remineralization to be $1.4 \mathrm{~mol} \mathrm{~N} \mathrm{~m}^{-2}$, which is three times the annual new production for the region (Jenkins and Goldman, 1985). In POC export terms, this would be 4.6-9.3 $\mathrm{mol} \mathrm{C}^{-2}$. If this export event was spread over a 30-90 day bloom for example, it would require a POC flux (and remineralization) of 50-300 $\mathrm{mmol} \mathrm{C} \mathrm{m}^{-2} \mathrm{~d}^{-}$ 1, well above any measured POC flux estimates during EDDIES or at BATS. In fact this flux number is so high relative to natural blooms, it implies a much longer period of high POC flux. The same type of calculations by McGillicuddy et al. (2007) for the $\mathrm{O}_{2}$ minimum at $800 \mathrm{~m}$ in the

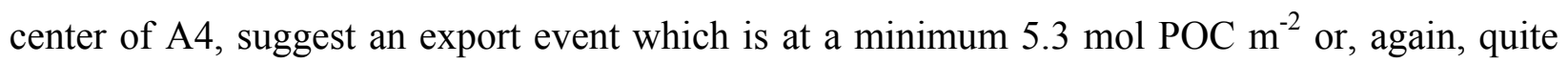
large relative to our observed summertime POC fluxes at $150 \mathrm{~m}$. This discrepancy would be exacerbated by any attenuation of flux with depth (Martin et al., 1987).

Another way to scale the observed flux to the deeper $\mathrm{O}_{2}$ anomaly, is to derive the impact of the observed summer POC flux on $\mathrm{O}_{2}$ remineralization. With a POC flux of 1-5 $\mathrm{mmol} \mathrm{C} \mathrm{m}^{-2} \mathrm{~d}^{-1}$, multiplied by Redfield stoichiometry of $138 \mathrm{O}_{2} / 106 \mathrm{C}$, this would be equivalent to a change in $\mathrm{O}_{2}$ of 1.3 to $6.5 \mathrm{mmol} \mathrm{m}^{-2} \mathrm{~d}^{-1}$. If remineralization occurred throughout a $200 \mathrm{~m}$ depth interval, 
this implies a concentration change of only 0.007 to $0.03 \mu \mathrm{mol} \mathrm{L}-1 \mathrm{~d}^{-1}$, i.e. the measured POC flux is much too small to support the local $\mathrm{O}_{2}$ minimum, insofar as the $20-40 \mu \mathrm{mol} \mathrm{L}{ }^{-1}$ oxygen deficit would constitute approximately a 2 to 16 year accumulation of the measured flux out of the euphotic zone (assuming no attenuation with depth).

It is worth noting that our average primary productivity $(\mathrm{PP})$ rates were $33,50,23,60 \mathrm{mmol} \mathrm{C}$ $\mathrm{m}^{-2} \mathrm{~d}^{-1}$ for E1, E2, E3, and E4, respectively (McGillicuddy et al., 2007). When compared to our POC fluxes from either traps or ${ }^{234} \mathrm{Th}$, the export/PP ratios range from $2-12 \%$, which are similar to BATS data, and not particularly high compared to other blooms or high latitude settings (Laws et al., 2000).

These scaling arguments indicate that the eddies induced large blooms either much earlier in time, and/or that the $\mathrm{O}_{2}$ anomaly had a distant source and is primarily an advective feature. Based on temperature and salinity on the isopycnal at which the oxygen anomaly resides, McGillicuddy et al., (2007) suggest potential origins of this low $\mathrm{O}_{2}$ water along the North or South limbs of the subtropical gyre. The southern source allows this to be primarily an advective feature, whereas the northern source requires a large eddy induced export event and is more consistent with the altimetric derived eddy trajectories from the north. Thorium-234 data tell us that if this was from a large flux event, it must have occurred at least two months prior to our arrival, otherwise the ${ }^{234} \mathrm{Th}$ activities we observed would have been significantly lower and rebounding as the flux decreased. Polonium-210 data have a longer "clock", but as mentioned, we do not have a constraint on prior POC $/{ }^{210} \mathrm{Po}$ conditions, though taken as a constant, the factor of 2-3 higher ${ }^{210} \mathrm{Po}$-derived flux here, is still much smaller than the factor of 10-50 higher POC 
fluxes needed to create these low $\mathrm{O}_{2}$ features (i.e. $50-300 \mathrm{mmol} \mathrm{C} \mathrm{m}^{-2} \mathrm{~d}^{-1}$ as estimated from $\mathrm{O}_{2}$ minima). Clearly to understand the full impact of eddies on the $\mathrm{C}$ balance of the Sargasso Sea, we will need observations much earlier in the eddy's life cycle.

\subsection{The A4 Diatom Bloom}

The central stations in eddy A4 were extraordinary in terms of phytoplankton biomass and species composition compared to the BATS mean summer conditions. Chlorophyll-a in the DCM was 8 standard deviations above the BATS mean (McGillicuddy et al., 2007) and total biomass, as measured by POC, was also at its maximum concentration in the DCM (data not shown). Bibby et al. (submitted, this volume) found the DCM at A4 to be dominated by diatoms with $>50 \%$ of the biomass in relatively larger $(>3 \mu \mathrm{m})$ cells. Microscopic analyses revealed that these diatoms were largely the chain-forming Chaetoceros spp. which had formed colonies in numbers that were 4-5 orders of magnitude greater than the background for BATS. This has also been confirmed by the spike in the diatom-specific accessory pigment Fucoxanthin (fucox) within the DCM (Figure 5b). During E3, total PP was only moderate, but significantly elevated during E4 over mean conditions in large part due to high rates of production in the DCM ( $66 \pm 9$ mmol C m $\mathrm{d}^{-2}$ for E4 vs. $35 \pm 17$ for BATS summer climatology).

The observed moderate POC flux, despite higher phytoplankton biomass (especially the diatom peak in the DCM core at A4 (Figure 5b)) can be explained by a number of processes. First, the link between phytoplankton biomass and export is not expected to be direct. Unless there is some limitation to growth or change in grazing pressure, these eddies can be at a stage where the community is in at least a temporary steady state with respect to biomass. Photosynthetic 
efficiency in A4, as gauged by Fv/Fm, was found to be 0.45 in the DCM and exhibiting a slightly negative correlation with total Chlorophyll-a concentrations throughout the eddy (Bibby et al., submitted, this volume). The explanation given for this trend is that the cells in the DCM were nutrient limited but still able to grow at low growth rates. This modest nutrient supply is thought to lead on balance to a significant build up of diatom biomass that is maintained for long periods of time during the later stages of a mode-water eddy's life cycle.

We also have in $\mathrm{A} 4$ an estimate of nutrient supply from a $\mathrm{SF}_{6}$ tracer study which determined the total upward flux of inorganic nitrogen into the DCM to be $0.6 \mathrm{mmol} \mathrm{N} \mathrm{m}^{-2} \mathrm{~d}^{-1}$ (Ledwell et al., submitted, this volume). This is 3.8 times higher than the downward flux of the PON in the $150 \mathrm{~m}$ sediment trap, and 3 times higher than the average PON flux derived from ${ }^{234} \mathrm{Th}$ (estimated from measured $\mathrm{C} / \mathrm{N}$ on $>53 \mu \mathrm{m}$ particles). This difference, if real, might be expected to result in a build up of DOC ( $\mathrm{Li}$ and Hansell, submitted, this volume) or biomass increases between cruises $\mathrm{C} 3$ and $\mathrm{C} 4$, but this was not seen (Figure 5). The biological pump also includes a role for zooplankton feeding and vertical migration as one alternative export pathway. Zooplankton biomass does appear elevated at A4 eddy center (Goldthwait and Steinberg, submitted, this volume), but the impact of enhanced biomass on vertical $\mathrm{C}$ exchange is not clear. While in theory, enhanced $\mathrm{C}$ export via migrating zooplankton might be a surface ocean $\mathrm{C}$ loss term that is missed by standard traps, removal of POC via zooplankton feeding should result in a ${ }^{234} \mathrm{Th}$ deficit that is not obvious in the A4 central eddy data. Even though we cannot balance input and losses better than a factor of two, taken together, both $\mathrm{SF}_{6}$ and our export estimates support the idea of Bibby et al. (submitted, this volume) that mode-water eddies supply a modest and patchy 
level of new nutrients enabling the build up of diatom biomass, but with low growth rates and minimal losses.

Though no significant enhancement of POC flux was seen associated with the diatom bloom, we might expect an impact on biogenic Si (bSi) flux. While we do not have direct measurement of $\mathrm{bSi}$ in the sediment traps, we did measure $\mathrm{bSi} /{ }^{234} \mathrm{Th}$ ratios on a small number of $53 \mu \mathrm{m}$ pore size filters from in-situ pumps at 120 and $150 \mathrm{~m}$ from $\mathrm{A} 4$, and see higher values in central $\left(\mathrm{bSi} /{ }^{234} \mathrm{Th}\right.$ $\left.=0.31 \mu \mathrm{mol} \mathrm{dpm}{ }^{-1}, \mathrm{n}=18\right)$ vs. eddy edge stations $\left(0.13 \mu \mathrm{mol} \mathrm{dpm}^{-1}, \mathrm{n}=7\right)$. Similar to POC, we can then estimate a bSi flux on sinking particles of $0.17 \pm 0.06 \mathrm{mmol} \mathrm{Si} \mathrm{m}^{-2} \mathrm{~d}^{-1}$ for central stations.

Unfortunately there are no regular bSi flux estimates at BATS for comparison, however a 22 month study of bSi in BATS traps in 1991-1992 was conducted which found an annual average

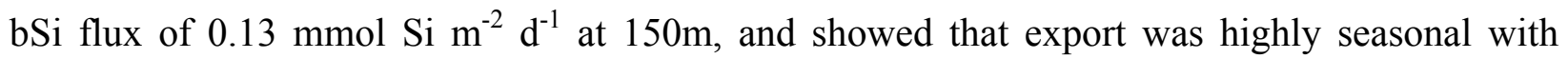
highest fluxes associated with a winter diatom bloom (Brzezinski and Nelson, 1995). Summer averages were about 0.05 and winter maxima were as high as $0.6 \mathrm{mmol} \mathrm{Si} \mathrm{m} \mathrm{m}^{-1}$. Our estimated bSi flux in the central A4 stations is thus $\sim 3$ times this summer average, but less than maximal rates seen at BATS (which occur during the winter/spring bloom). The higher bSi flux seen here in A4 associated with diatoms was also found in an eddy in the subtropical N. Pacific (BenitezNelson et al., 2007; Maiti et al., 2007) where a similar enhancement was measured in bSi flux using traps, and a lower bSi flux enhancement was estimated using the ${ }^{234} \mathrm{Th}$ method. These researchers conducted their study during the early stages of formation of a cyclonic eddy and concluded that there was enhanced bSi flux, but not necessarily higher POC export. While 
eddies in these subtropical gyres can enhance local diatom production and export, none of the eddy fluxes are high by standards of Southern Ocean diatom blooms, where bSi fluxes up to 10 mmol Si m $\mathrm{d}^{-1}$ are found and correspondingly high POC fluxes $>20 \mathrm{mmol} \mathrm{C} \mathrm{m}^{-2} \mathrm{~d}^{-1}$ at $100 \mathrm{~m}$ are found in the vicinity of the Polar Front (Buesseler et al., 2001b). Significantly higher POC fluxes are also found for short periods following the spring diatom bloom in the North Atlantic (10-40 mmol C m $\mathrm{d}^{-1}$ Buesseler et al., 1992).

\subsection{Vertical layering of export and shallow remineralization}

With multiple closely spaced stations and higher vertical resolution, we see layering of ${ }^{234} \mathrm{Th}$ depletion and excess that does indicate significant vertical structure of either physical or biologically enhanced particle export and remineralization. We suspect, but cannot prove that biological layering of the primary particle producers and heterotrophic grazers is ultimately responsible for this pattern (Cowles et al., 1998). Similar layering and submesoscale structure is evident in many of the EDDIES data sets, including bacteria biomass and productivity (Ewart et al., submitted, this volume), nutrients (Li and Hansell, submitted, this volume), phytoplankton pigments and photophysiology (Bibby et al., submitted, this volume), bio-optics (Siegel et al., submitted, this volume), zooplankton (Goldthwait and Steinberg, submitted, this volume) and high resolution towed sensor and Video Plankton Recorder (VPR) data (e.g. McGillicuddy et al., 2007). Given the high level of patchiness within the eddy, it is difficult to compare data that were not collected from the exact same CTD and Niskin bottle. Also it is important to remember that the response time for change varies whether we are talking about an instantaneous rate measurement, build up of phytoplankton stocks, zooplankton grazing, gas or nutrient fields, and radioactive tracers with various half lives. 
The approach taken here to study these layers relies on isopycnal mapping of property features from the same $R V$ Weatherbird II sample bottles and transects across the eddy features. These isopycnal plots show distinct layering and alignment of chlorophyll-a at the DCM, and immediately below, a layer of ${ }^{234} \mathrm{Th}$ excess at the onset of the nutricline (Figure $5 \mathrm{a}$ and $\mathrm{b}$ ). This layer of excess ${ }^{234} \mathrm{Th}$ has not been previously identified in the Sargasso Sea, and is typically only poorly resolved by a small number of samples in other studies (Bacon et al., 1996; Rutgers van der Loeff et al., 2002; Usbeck et al., 2002; Savoye et al., 2004; Buesseler et al., 2005). With a 24 day half life, this must also be an ongoing/recent event. Also interesting is that higher excess ${ }^{234} \mathrm{Th}$ is found on cruises with the highest deep chlorophyll-a concentrations, namely E3 and E4.

We can think of de novo formation of particles as largely driven by autotrophic processes in the euphotic zone and remineralization as the heterotrophic consumption of sinking particles in both the euphotic zone and below. In this case, the ${ }^{234} \mathrm{Th}$ excess peak immediately below the DCM can be explained as being the depth at which particle formation has stopped but heterotrophic consumption of labile organic rich particles still proceeds at high rates. For example, microbial degradation by attached bacteria would continue as particles sink, releasing DOM and at least slowing down net settling rates through particle break-up and dissolution processes. Zooplankton detrital feeders would also obtain maximal energy from feeding on organic rich particles in shallower waters. Due to these combined processes, total flux attenuates most rapidly with depth in the upper ocean. At some point, the change in the total ${ }^{234} \mathrm{Th}$ budget due to its supply on sinking particles is too small to see as a perturbation in the total ${ }^{234} \mathrm{Th}:{ }^{238} \mathrm{U}$ ratio. This point is reached quickly as the flux decreases, since $<1 \%$ of the total ${ }^{234} \mathrm{Th}$ activity is on the 
larger and faster sinking particles (data not shown) and a small flux is insufficient to draw down total ${ }^{234} \mathrm{Th}$ relative to its production and decay rates.

Using these ${ }^{234} \mathrm{Th}$ data, we can compare the flux into this zone of excess ${ }^{234} \mathrm{Th}$ with the flux out, to quantify the magnitude of $\mathrm{C}$ and nutrient remineralization within this layer. The remineralization signal is most striking during E3, where we calculate ${ }^{234} \mathrm{Th}$ and POC flux at a density of $26.26 \mathrm{~kg} \mathrm{~m}^{-3}$ (center of DCM; 120m) and then from 26.26 to $26.4 \mathrm{~kg} \mathrm{~m}^{-3}$ (120-300m). The ${ }^{234} \mathrm{Th}$ flux for E3 drops by more than half between 120 and 300m, from 564 to $211 \mathrm{dpm} \mathrm{m}^{-2}$ $\mathrm{d}^{-1}$. We don't see any significant change in POC/ ${ }^{234} \mathrm{Th}$ on the $>53 \mu \mathrm{m}$ particles between $150-$ 300m during E3, thus the change in POC flux would be on the same order, dropping from about $1.5-2$ to $<0.75 \mathrm{mmol} \mathrm{C} \mathrm{m}^{-2} \mathrm{~d}^{-1}$. For the other cruises, this excess ${ }^{234} \mathrm{Th}$ feature is clear in the combined data, but not at every station. There is also evidence of remineralization in enhanced $\mathrm{N}$ :Si ratios in the dissolved nutrient fields in this same deeper, 120-300m layer (data not shown). We hypothesize that the $\mathrm{N}: \mathrm{Si}$ increases due to preferential remineralization of $\mathrm{N}$ in sinking particles vs. Si, which is carried by more resistant silicate biominerals. A similar conclusion was reached in the NW Pacific based upon enhanced N:Si ratios below the DCM (Buesseler et al., 2007b).

A deeper feature worth discussion is the ${ }^{234} \mathrm{Th}$ minima at the bottom of many profiles in the 300m samples, especially during E1, E2 and E4. As discussed in Section 3.1., we do not have sufficient resolution to see the vertical extent of this feature, but we have enough data to suggest that it is a common feature, and not associated preferentially with either central or edge stations. 
This is not a signal resulting from continued remineralization, since without ${ }^{234} \mathrm{Th}$ removal, the ${ }^{234} \mathrm{Th}:{ }^{238} \mathrm{U}$ ratio can only be 1 or greater.

There are three possible reasons to find a ${ }^{234} \mathrm{Th}$ deficit below the euphotic zone. First, it is possible that zooplankton detrital feeders are actively repackaging suspended POM in to sinking particles at this depth, thus causing an enhanced ${ }^{234} \mathrm{Th}$ loss to sinking particles and measurable reduction in total ${ }^{234} \mathrm{Th}:{ }^{238} \mathrm{U}$. Unfortunately, the zooplankton net sampling program during EDDIES was not of sufficient vertical resolution to tease out zooplankton biomass differences in this low ${ }^{234} \mathrm{Th}$ layer at $300 \mathrm{~m}$ (Goldthwait and Steinberg, submitted, this volume). A second process might be enhanced physical aggregation leading to preferential export at this depth, but there is no density discontinuity associated with this feature that might enhance particle contact or residence times, so this seems unlikely, but cannot be ruled out. A third possibility is a sampling artifact, due to undersampling of zooplankton that are known to swim away and thus avoid capture in standard CTD bottles. For this to cause $\mathrm{a}^{234} \mathrm{Th}$ minimum, a significant fraction of the ${ }^{234} \mathrm{Th}$ inventory would have to be associated with zooplankton biomass. However in the case of ${ }^{234} \mathrm{Th}$, the zooplankton ${ }^{234} \mathrm{Th}$ concentrations are in fact quite low (Rodriguez y Baena et al., 2007). Also, we would expect this potential artifact to be higher for ${ }^{210} \mathrm{Po}$, which is highly concentrated in zooplankton biomass, but we did not see a minimum for ${ }^{210} \mathrm{Po}$ at this same depth (Figure 10). We therefore rule out this third possible explanation for low ${ }^{234} \mathrm{Th}$ at depth, and consider the zooplankton detrital feeding to be the most likely process causing the ${ }^{234} \mathrm{Th}$ minima at $300 \mathrm{~m}$. Additional study of these deeper export layers is warranted in future studies now that they can be readily identified with these improved ${ }^{234} \mathrm{Th}$ methods. 


\section{CONCLUSIONS}

We used three independent methods to assess particle fluxes associated with a cyclonic and mode-water eddy in the Sargasso Sea. Total POC fluxes in these eddies were not elevated relative to the BATS summertime mean conditions. These data do not contradict the finding of low $\mathrm{O}_{2}$ below both eddies, which is thought to be due to eddy enhanced POC flux and remineralization (McGillicuddy et al., 2007). Rather, the flux methods we used integrate over shorter time scales and thus provide a strong constraint on the timing of the higher flux event, which must have taken place at least 2 months or more prior to our extended summer observations. We conclude that in terms of export, both $\mathrm{C} 1$ and $\mathrm{A} 4$ were observed during a later period of their life cycle when POC export was low. Neither flux is high enough to balance annual new production for the Sargasso Sea or the observed $\mathrm{O}_{2}$ minima directly below both eddies. Thus mature eddies as observed here, cannot be used to close C budgets in the Sargasso Sea as they have little impact on the net efficiency of the biological pump for carbon.

Relative to BATS mean conditions, the biomass and diatom abundances were high in the center of A4. The diatom response to this mode-water eddy appears more similar to the early eddy stages of a cyclonic eddy in the subtropical Pacific (Benitez-Nelson et al., 2007). In this mature stage of the A4 eddy life cycle phytoplankton photosynthetic efficiency is not optimal (Bibby et al., submitted, this volume). In this quasi steady state phase, there is 2-3 times higher bSi export relative to BATS summer averages, but no significant impact on POC flux associated with this eddy induced diatom bloom in the Sargasso Sea. The observed PON flux derived from measured $\mathrm{C} / \mathrm{N}$ is about half the upward flux of dissolved nutrients implied by tracer injections in the A4 nutricline (Ledwell et al., submitted, this volume). Although it may be coincidental, it is curious 
that the mismatch between particle export and nutrient supply in eddy A4 mimics the same aspect of the longer-term mean budgets at BATS referred to in the INTRODUCTION (Section 1.), i.e. the observed particle export is systematically lower than new production inferred from tracer budgets.

Finally, the high vertical and spatial resolution obtained with new ${ }^{234} \mathrm{Th}$ methods allows us to see layering of export and remineralization better than in prior studies. We see layering of ${ }^{234} \mathrm{Th}$ removal in the euphotic zone, and a strong excess ${ }^{234}$ Th peak immediately below the DCM. We attribute this excess ${ }^{234} \mathrm{Th}$ to rapid remineralization of the labile sinking material that is formed in the euphotic zone immediately above. In terms of the sinking POC flux, there is $65 \%$ decrease in the POC flux between 120 and 300m (calculated from A4 cruise E3). An unexplained ${ }^{234} \mathrm{Th}$ deficit was found in many of the stations at 300m implying additional particle aggregation and/or detrital packaging by heterotrophs at deeper depths. We are just beginning to see new features in the upper ocean particle cycle with high resolution ${ }^{234} \mathrm{Th}$ data. In EDDIES, these data showed spatially variable export and remineralization fields, but in the vertical, narrowly defined layers of export and remineralization that remained in place over the two month occupations of these mature eddy features. Additional work to look at these layers and eddies earlier in their life cycle are suggested by these results.

\section{ACKNOWLEDGEMENTS}

The EDDIES project was funded by the National Science Foundation Chemical, Biological, and Physical Oceanography Programs. Additional support for HPLC pigment analysis (Dr. Charles Trees, CHORS) was provided by NASA. We are pleased to acknowledge the excellent at sea 
support from the officers and crew of the $R V$ Weatherbird II. There are a number of individuals who also deserve credit for the success of this program and manuscript preparation including: John Andrews, Sheila Clifford, Paul Henderson, Brian Pointer, and Dave Schneider. Thoughtful comments during review by M. Rutgers van der Loeff, one anonymous reviewer and the guest editor, Claudia Benitez-Nelson, helped to significantly improve this manuscript. 


\section{REFERENCES}

Amiel, D., Cochran, J.K., Hirschberg, D.J., 2002. ${ }^{234} \mathrm{Th} /{ }^{238} \mathrm{U}$ disequilibrium as an indicator of the seasonal export flux of particulate organic carbon in the North Water. Deep-Sea Research II 49, 5191-5209.

Bacon, M.P., Spencer, D.W., Brewer, P.G., 1976. ${ }^{210} \mathrm{~Pb} /{ }^{226} \mathrm{Ra}$ and ${ }^{210} \mathrm{Po} /{ }^{210} \mathrm{~Pb}$ disequilibria in seawater and suspended particulate matter. Earth and Planetary Science Letters 32, 277-296.

Bacon, M.P., Cochran, J.K., Hirschberg, D., Hammar, T.R., Fleer, A.P., 1996. Export flux of carbon at the equator during the EqPac time-series cruises estimated from ${ }^{234} \mathrm{Th}$ measurements. Deep-Sea Research II 43, 1133-1154.

Benitez-Nelson, C., Moore, W.S., 2006. Future Applications of ${ }^{234} \mathrm{Th}$ in aquatic ecosystems. Marine Chemistry 100, 163-165.

Benitez-Nelson, C., Buesseler, K.O., Rutgers van der Loeff, M., Andrews, J., Ball, L., Crossin, G., Charette, M., 2001a. Testing a new small-volume technique for determining thorium-234 in seawater. Journal of Radioanalytical and Nuclear Chemistry 248(3), 795-799.

Benitez-Nelson, C., Buesseler, K.O., Karl, D., Andrews, J., 2001b. A time-series study of particular matter export in the North Pacific Subtropical Gyre based upon ${ }^{234} \mathrm{Th}:{ }^{238} \mathrm{U}$ disequilibrium. Deep-Sea Research I 48(12), 2595-2611.

Benitez-Nelson, C.R., Bidigare, R.R., Dickey, T.D., Landry, M.R., Leonard, C.L., Brown, S.L., Nencioli, F., Rii, Y.M., Maiti, K., Becker, J.W., Bibby, T.S., Black, W., Cai, W.-J., Carlson, C., Chen, F.Z., Kuwahara, V.S., Mahaffey, C., McAndrew, P.M., Quay, P.D., Rappé, M.S., Selph, K.E., Simmons, M.E., Yang, E.J., 2007. Eddy-induced diatom bloom drives increased biogenic silica flux, but inefficient carbon export in the subtropical North Pacific Ocean. Science, 316, 1017-1021.

Bibby, T.S., Gorbunov, M.Y., Wyman, K.W., Falkowski, P.G.. Photosynthetic community responses to upwelling mesoscale eddies in the subtropical north Atlantic and Pacific Oceans. Deep-Sea Research II submitted, this volume.

Brzezinski, M.A., Nelson, D.M., 1995. The Annual Silica Cycle in the Sargasso Sea near Bermuda. Deep-Sea Research Part I-Oceanographic Research Papers 42 (7), 1215-1237.

Buesseler, K.O., Bacon, M.P., Cochran, J.K., Livingston, H.D., 1992. Carbon and nitrogen export during the JGOFS North Atlantic Bloom Experiment estimated from ${ }^{234} \mathrm{Th}:{ }^{238} \mathrm{U}$ disequilibria. Deep-Sea Research I 39 (7-8), 1115-1137.

Buesseler, K., Michaels, A.F., Siegel, D.A., Knap, A.H., 1994. A three dimensional timedependent approach to calibrating sediment trap fluxes. Global Biogeochemical Cycles 8 (2), 179-193.

Buesseler, K.O., Steinberg, D.K., Michaels, A.F., Johnson, R.J., Andrews, J.E., Valdes, J.R., Price, J.F., 2000. A comparison of the quantity and quality of material caught in a neutrally buoyant versus surface-tethered sediment trap. Deep-Sea Research I 47, 277-294.

Buesseler, K.O., Benitez-Nelson, C., Rutgers van der Loeff, M., Andrews, J., Ball, L., Crossin, G., Charette, M., 2001a. An intercomparison of small- and large-volume techniques for thorium-234 in seawater. Marine Chemistry 74(1), 15-28.

Buesseler, K.O., Ball, L., Andrews, J., Cochran, J.K., Hirschberg, D.J., Bacon, M.P., Fleer, A., Brzezinski, M., 2001b. Upper ocean export of particulate organic carbon and biogenic silica in the Southern Ocean along $170^{\circ} \mathrm{W}$. Deep-Sea Research II 48, 4275-4297. 
Buesseler, K.O., Andrews, J.E., Pike, S., Charette, M.A., Goldson, L.E., Brzezinski, M.A., Lance, V.P., 2005. Particle export during the Southern Ocean Iron Experiment (SOFeX). Limnology and Oceanography 50, 311-327.

Buesseler, K.O., Benitez-Nelson, C.R., Moran, S.B., Burd, A., Charette, M., Cochran, J.K., Coppola, L., Fisher, N.S., Fowler, S.W., Gardner, W.D., Guo, L.D., Gustafsson, O., Lamborg, C., Masque, P., Miquel, J.C., Passow, U., Santschi, P.H., Savoye, N., Stewart, G., Trull, T., 2006. An assessment of particulate organic carbon to thorium-234 ratios in the ocean and their impact on the application of ${ }^{234} \mathrm{Th}$ as a POC flux proxy. Marine Chemistry 100, (3-4), 213-233.

Buesseler, K.O., Antia, A.N., Chen, M., Fowler, S.W., Gardner, W.D., Gustafsson, O., Harada, K., Michaels, A.F., Loeff, M.R.v.d., Sarin, M., Steinberg, D.K., Trull, T., 2007a. An assessment of the use of sediment traps for estimating upper ocean particle fluxes. Journal of Marine Research, 65(3), 345-416.

Buesseler, K.O., Trull, T.W., Steinberg, D.K., Silver, M.W., Siegel, D.A., Saitoh, S.-I., Lamborg, C.H., Lam, P.J., Karl, D.M., Jiao, N.Z., Honda, M.C., Elskens, M., Dehairs, F., Brown, S.L., Boyd, P.W., Bishop, J.K.B., Bidigare, R.R., 2007b. VERTIGO (VERtical Transport In the Global Ocean): a study of particle sources and flux attenuation in the North Pacific. Deep-Sea Research II, submitted.

Cai, P., Dai, M., Chen, W., Tang, T., Zhou, K., 2006. On the importance of the decay of ${ }^{234}$ Th in determining size-fractionated $\mathrm{C} /{ }^{234} \mathrm{Th}$ ratio on marine particles. Geophysical Research Letters 33, L23602, doi:10.1029/2006GL027792.

Chen, J.H., Edwards, R.L., Wasserburg, G.J., 1986. ${ }^{238} \mathrm{U},{ }^{234} \mathrm{U}$ and ${ }^{232} \mathrm{Th}$ in seawater. Earth and Planetary Science Letters 80, 241-251.

Coale, K.H., 1990. Labyrinth of doom: A device to minimize the "swimmer" component in sediment trap collections. Limnology Oceanography 35(6), 1376-1381.

Cochran, J.K., Buesseler, K., Bacon, M.P., Wang, H.W., Hirschberg, D.J., Ball, L., Andrews, J., Crossin, G., Fleer, A., 2000. Short-lived thorium isotopes $\left({ }^{234} \mathrm{Th},{ }^{228} \mathrm{Th}\right)$ as indicators of POC export and particle cycling in the Ross Sea, Southern Ocean. Deep-Sea Research II 47(1516), 3451-3490.

Cochran, J.K., Masqué, P., 2003. Short-lived U/Th series radionuclides in the ocean: Tracers for scavenging rates, export fluxes and particle dynamics. Reviews in Mineralogy and Geochemistry 52, 461-492.

Cowles, T.J., Desiderio, R.A. and Carr, M.E., 1998. Small-scale planktonic structure: persistence and trophic consequences. Oceanography 11(1), 4-9.

Doney, S.C., 1996. A synoptic atmospheric surface forcing data set and physical upper ocean model for the US JGOFS Bermuda Atlantic Time-Series Study site. Journal of Geophysical Research-Oceans 101, (C11), 25615-25634.

Ewart, C.S., Meyers, M.K., Wallner, E., McGillicuddy, D.J., and C. A. Carlson. Bacterioplankton Dynamics in Cyclonic and Anticyclonic Mode-Water Eddies in the Northwestern Sargasso Sea. Deep-Sea Research II, submitted, this volume.

Fisher, N.S., Burns, K.A., Cherry, R.D., Heyraud, M., 1983. Accumulation and cellular distribution of ${ }^{241} \mathrm{Am},{ }^{210} \mathrm{Po}$ and ${ }^{210} \mathrm{~Pb}$ in two marine algae. Marine Ecology Progress Series $11,233-237$.

Gardner, W.D., 2000. Sediment Trap Technology and Sampling in Surface Waters. In: Hanson, R.B., Ducklow, H.W., Field, J.G. (Eds.), The Changing Ocean Carbon Cycle: A Midterm Synthesis of the Joint Global Ocean Flux Study, pp. 240-281. 
Goldthwait, S., Steinberg, D., 2007. Elevated Biomass of Mesozooplankton and Enhanced Fecal Pellet Flux in Cyclonic and Mode-Water Eddies in the Sargasso Sea, Deep-Sea Research II, submitted, this volume.

Hung, C.-C., Guo, L.D., Roberts, K.A., Santschi, P.H., 2004. Upper ocean carbon flux determined by size-fractionated ${ }^{234}$ Th data and sediment traps in the Gulf of Mexico. Geochemical Journal 38 (6), 601-611.

Jenkins, W.J., 1988a. Nitrate flux into the euphotic zone near Bermuda. Nature 331, 521-523.

Jenkins, W.J., 1988b. The use of anthropogenic tritium and helium-3 to study subtropical ventilation and circulation. Philosophical Transactions of the Royal Society of London Series A-Mathematical Physical and Engineering Sciences 325, 43-61.

Jenkins, W.J. and Goldman, J.C., 1985. Seasonal oxygen cycling and primary production in the Sargasso Sea. Journal of Marine Research 43, (2), 465-495.

Karl, D.M., Christian, J.R., Dore, J.E., Hebel, D.V., Letelier, R.M., Tupas, L.M., Winn, C.D., 1996. Seasonal and interannual variability in primary production and particle flux at Station ALOHA. Deep-Sea Research II 43(2-3), 539-568.

Kharkar, D.P., Thomson, J., Turekian, K.K., Forster, W.O., 1976. Uranium and thorium decay series nuclides in plankton from the Caribbean. Limnology and Oceanography 21, 294-299.

Kim, G., and Church, T.M., 2001. Seasonal biogeochemical fluxes of Th-234 and Po-210 in the upper Sargasso Sea: Influence from atmospheric iron deposition. Global Biogeochemical Cycles 15, (3), 651-661.

Knauer, G.A., Martin, J.H., and Bruland, K.W., 1979. Fluxes of particulate carbon, nitrogen, and phosphorous in the upper water column of the northeast Pacific. Deep-Sea Research 26, 97 108.

Laws, E.A., Falkowski, P.G., Smith Jr., W.O., Ducklow, H., McCarthy, J.J., 2000. Temperature effects on export production in the open ocean. Global Biogeochemical Cycles 14(4), 12311246.

Ledwell, J.R., McGillicuddy, D.J., Anderson, L.A., 2007. Nutrient flux into an intense deep chlorophyll layer in a mode-water eddy. Deep-Sea Research II, submitted, this volume.

Li, Q.P. and Hansell, D.A., 2007. Interaction of nutrients and chlorophyll biomass in baroclinic eddies of the oligotrophic North Atlantic. Deep-Sea Research II, submitted, this volume.

Martin, J.H., Knauer, G.A., Karl, D.M., Broenkow, W.W., 1987. VERTEX: carbon cycling in the northeast Pacific. Deep-Sea Research 34, 267-285.

Masqué, P., Sanchez-Cabeza, J.A., Bruach, J.M., Palacios, E., Canals, M., 2002. Balance and residence times of ${ }^{210} \mathrm{~Pb}$ and ${ }^{210} \mathrm{Po}$ in surface waters of the northwestern Mediterranean Sea. Continental Shelf Research 22, 2127-2146.

McGillicuddy, D.J. Jr. and Robinson, A.R., 1997. Eddy-induced nutrient supply and new production in the Sargasso sea. Deep-Sea Research Part I-Oceanographic Research Papers 44, (8), 1427-1450.

McGillicuddy, D.J. Jr, Robinson, A.R., Siegel, D.A., Jannasch, H.W., Johnson, R., Dickey, T.D., McNeil, J., Michaels, A.F., Knap, A.H. 1998. Influence of mesoscale eddies on new production in the Sargasso Sea. Nature, 394, 6690, 263-266.

McGillicuddy, D.J. Jr., Anderson, L.A., Bates, N.R., Bibby, T., Buesseler, K.O., Carlson, C., Davis, C.S., Ewart, C., Falkowski, P.G., Goldthwait, S.A., Hansell, D.A., Jenkins, W.J., Johnson, R., Kosnyrev, V.K., Ledwell, J.R., Li, Q.P., Siegel, D.A., Steinberg, D.K., 2007. Eddy-wind interactions stimulate extraordinary mid-ocean plankton blooms. Science,316, 1021-1026. 
Michaels, A.F., Knap, A.H., 1996. Overview of the U.S. JGOFS Bermuda Atlantic Time-series Study and the Hydrostation S program. Deep-Sea Research II 43(2-3), 157-198.

Michaels, A.F., Bates, N.R., Buesseler, K.O., Carlson, C.A., Knap, A.H., 1994. Carbon-cycle imbalances in the Sargasso Sea. Nature 372, 537-540.

Mouriño-Carballido, B., McGillicuddy, D.J., 2006. Mesoscale variability in the metabolic balance of the Sargasso Sea. Limnology and Oceanography 51, (6), 2675-2689.

Oschlies, A., 2002. Can eddies make ocean deserts bloom?, Global Biogeochemical Cycles, 16(4), 1106, doi:10.1029/2001GB001830.

Oschlies, A., Garcon, V., 1998. Eddy-induced enhancement of primary production in a model of the North Atlantic Ocean. Nature 394, 266-269.

Pates, J.M., Muir, G.K.P., 2007. U-salinity relationships in the Mediterranean: Implications for ${ }^{234} \mathrm{Th}:{ }^{238} \mathrm{U}$ particle flux studies. Marine Chemistry 106, 530-545.

Pike, S., Buesseler, K.O., Andrews, J.A., Savoye, N., 2005. Quantification of ${ }^{234}$ Th recovery in small volume sea water samples by inductively coupled plasma mass spectrometry. Journal of Radioanalytical and Nuclear Chemistry 263 (2), 355-360.

Rodriguez y Baena, A.M., Fowler, S.W., Miquel, J.C., 2007. Particulate organic carbon:natural radionuclide ratios in zooplankton and their freshly produced fecal pellets from the NW Mediterranean (MedFlux 2005), Limnology \& Oceanography in press.

Rutgers van der Loeff, M.M., Buesseler, K.O., Bathmann, U., Hense, I., Andrews, J., 2002. Comparison of carbon and opal export rates between summer and spring bloom periods in the region of the Antarctic Polar Front, SE Atlantic. Deep-Sea Research II 49(18), 38493870 .

Rutgers van der Loeff, M., Sarin, M.M., Baskaran, M., Benitez-Nelson, C., Buesseler, K., Charette, M., Dai, M., Gustafsson, Ö., Masque, P., Morris, P., Orlandini, K., Rodriguez y Baena, A., Savoye, N., Schmidt, S., Turnewitsch, R., Vöge, I., Waples, J., 2006. New methodologies and techniques for ${ }^{234}$ Th analysis. Marine Chemistry 100, 190-212.

Savoye, N., Buesseler, K.O., Cardinal, D., Dehairs, F., 2004. 234Th deficit and excess in the Southern Ocean during spring 2001: particle export and mineralization. Geophysical Research Letters 31, L12301, doi: 10.1029/2004GL019744.

Savoye, N., Benitez-Nelson, C., Burd, A.B., Cochran, J.K., Charette, M., Buesseler, K.O., Jackson, G., Roy-Barman, M., Schmidt, S., Elskens, M., 2006. An overview of techniques used to model ${ }^{234} \mathrm{Th}$ in the water column. Marine Chemistry 100, 234-249.

Shannon, L.V., Cherry, R.D., Orren, M.J., 1970. Polonium-210 and lead-210 in the marine environment. Geochimica et Cosmochimica Acta 34, 701-711.

Siegel, D.A., McGillicuddy Jr., D.J., Fields, E.A., 1999. Mesoscale eddies, satellite altimetry and new production in the Sargasso Sea. Journal of Geophysical Research 104 (C6), 13,359313,379.

Siegel, D.A., Court, D.B., Menzies, D.W., Peterson, P., Maritorena, S., Nelson, N.B. Satellite and in situ observations of the bio-optical signatures of two mesoscale eddies in the Sargasso Sea. Deep-Sea Research II, submitted, this volume.

Stanley, R.H.R., Buesseler, K.O., Manganini, S.J., Steinberg, D.K., Valdes, J.R., 2004. A comparison of major and minor elemental fluxes collected using neutrally buoyant and surface-tethered traps. Deep Sea Research I, 51, 1387-1395.

Steinberg, D.K., Carlson, C.A., Bates, N.R., Johnson, R.J., Michaels, A.F., Knap, A.H., 2001. Overview of the US JGOFS Bermuda Atlantic Time-series Study (BATS): a decade-scale 
look at ocean biology and biogeochemistry. Deep-Sea Research Part II-Topical Studies in Oceanography, 48 (8-9), 1405-1448.

Stewart, G.M., Fisher, N.S., 2003a. Experimental studies on the accumulation of polonium-210 by marine phytoplankton. Limnology and Oceanography 43 (3), 1193-1201.

Stewart, G.M., Fisher, N.S., 2003b. Bioaccumulation of polonium-210 in marine copepods Limnology and Oceanography 48 (5), 2011-2019.

Stewart, G.M., Fowler, S.W., Teyssie, J.-L., Cotret, O., Cochran, J.K., Fisher, N.S., 2005. Contrasting the transfer of polonium-210 and lead-210 across three trophic levels in the marine plankton. Marine Ecology Progress Series, 290, 27-33.

Stewart, G., Cochran, J.K., Miquel, J.C., Masqué, P., Szlosek, J., Rodriguez y Baena, A.M., Fowler, S.W., Gasser, B., Hirschberg, D.J., 2007. Comparing POC export from ${ }^{234} \mathrm{Th} /{ }^{238} \mathrm{U}$ and ${ }^{210} \mathrm{Po} /{ }^{210} \mathrm{~Pb}$ disequilibria with estimates from sediment traps in the northwest Mediterranean. Deep-Sea Research I, 54(9), 1549-1570.

Sweeney, E.N., McGillicuddy, D.J., Buesseler, K.O., 2003. Biogeochemical impacts due to mesoscale eddy activity in the Sargasso Sea as measured at the Bermuda Atlantic Time Series (BATS) Site. Deep-Sea Research II 50, 3017-3039.

Usbeck, R., Rutgers van der Loeff, M., Hoppema, M., Schlitzer, R., 2002. Shallow remineralization in the Weddell Gyre. Geochemistry, Geophysics, Geosystems, v3, n1,doi: 10.1029/2001GC000182.

Verdeny, E., Masque, P., Maiti, K., Garcia-Orellanal, J., Bruach, J.M., Benitez-Nelson, C.R., 2007. Particle export within cyclonic Hawaiian lee eddies derived from ${ }^{210} \mathrm{~Pb}^{210} \mathrm{Po}$ disequilibria. Deep Sea Research Part II, submitted, this volume.

Verdeny, E., Masqué, P., Garcia-Orellana, J., Hanfland, C., Cochran, J.K. and Stewart, G.M. POC export form ocean surface waters by means of ${ }^{234} \mathrm{Th} /{ }^{238} \mathrm{U}$ and ${ }^{210} \mathrm{Po} /{ }^{210} \mathrm{~Pb}$ disequilibria: a comparison of two radiotracer pairs. Submitted to Deep-Sea Research II.

Volk, T., Hoffert, M.I., 1985. Ocean carbon pumps: Analysis of relative strengths and efficiencies in ocean-drive atmospheric $\mathrm{CO}_{2}$ changes. Geophysical Monographs 32, 99-110.

Williams, R.G., Follows, M.J., 2003. Physical transport of nutrients and the maintenance of biological production. In: Ocean Biogeochemistry; the role of the ocean carbon cycle in global change, Fasham, M.J.R., ed., IGBP series, Springer-Verlag, Berlin, ISBN: 3540423982 . 


\section{Figure Captions}

Figure 1. Map showing location and ID\# for CTD stations where ${ }^{234}$ Th samples were collected relative to the sea level anomaly (SLA mm scale on right differs for each eddy). $R V$ Weatherbird II cruise ID and SLA dates are indicated above each plot, with cyclonic eddy C1 cruises E1 (left) and E2 (right) on top row, and mode-water eddy A4 cruises E3 (left) and E4 (right) on bottom row. The dark lines on each map indicate the track for the drifting sediment traps deployed during EDDIES.

Figure 2. Histogram of ${ }^{234} \mathrm{Th}$ recoveries for 422 samples analyzed during EDDIES. Note ${ }^{230} \mathrm{Th}$ tracer was not calibrated on an absolute scale better than $5 \%$ (hence some recoveries $>100 \%$ ), but still can be used to determine the relative differences in thorium chemical extraction efficiency between each sample with a precision $<2 \%$.

Figure 3. Plots of property vs. depth for representative central stations for $\mathrm{C} 1$ cruises $\mathrm{E} 1$ (CTD\#7, top left), E2 (CTD\#8, bottom left), A4 cruises E3 (CTD\#18, top right) and E4 (CTD\#5, bottom right). Plotted in pairs of two panels with total ${ }^{234} \mathrm{Th}\left(\mathrm{dpm} \mathrm{L} \mathrm{L}^{-1}\right.$; filled symbols) with error bars connected by black dashed line on left, along with ${ }^{238} \mathrm{U}$ (dpm $\mathrm{L}^{-1}$; dotted line) and density (sigma-t units $\mathrm{kg} \mathrm{m}^{-3}$ ) as grey dashed line in same panel. Right panel shows total chlorophyll-a ( $\mu \mathrm{g} \mathrm{kg}^{-1}$; filled symbols) and sum of $\mathrm{NO}_{3} \& \mathrm{NO}_{2}\left(\mu \mathrm{mol} \mathrm{kg}{ }^{-1}\right.$; gray symbols) for the same CTD cast as on left.

Figure 4. Contour plots (from top to bottom) of salinity, ${ }^{234} \mathrm{Th}\left(\mathrm{dpm} \mathrm{L} \mathrm{L}^{-1}\right)$, dissolved $\mathrm{O}_{2}\left(\mu \mathrm{mol} \mathrm{kg}{ }^{-1}\right)$, and chlorophyll-a $\left(\mu \mathrm{g} \mathrm{kg}^{-1}\right)$. Four panels on left are from a single transect across eddy $\mathrm{C} 1$, and panels on right from a single transect across eddy A4 (CTD\# along bottom X-axis; see Fig. 1 for station locations). Note all scales are the same between left and right pairs, except for salinity which is different to highlight the impact of eddies on physical properties.

Figure 5. Property vs. density (sigma-t units $\mathrm{kg} \mathrm{m}^{-3}$ ) plots for selected eddy transects. Figure 5a. eddy C1 cruises E1 (4 left panels), E2 (4 right panels); and Figure 5b. eddy A4, cruises E3 (4 left panels) and E4 (4 right panels). For each cruise the same four parameters are plotted and on the same scales. Parameters are, from top to bottom, chlorophyll-a $\left(\mu \mathrm{g} \mathrm{kg}^{-1}\right)$, Fucoxanthanin $\left(\mu \mathrm{g} \mathrm{kg}^{-}\right.$ $\left.{ }^{1}\right)$, sum of $\mathrm{NO}_{3} \& \mathrm{NO}_{2}\left(\mu \mathrm{mol} \mathrm{kg}{ }^{-1}\right)$ and ${ }^{234} \mathrm{Th}\left(\mathrm{dpm} \mathrm{L} \mathrm{L}^{-1}\right.$; w ${ }^{238} \mathrm{U}$ as smaller dots at activities near 2.6). In each plot, filled symbols are central eddy stations, and open symbols are other stations within the eddy and edge stations. The vertical line through each panel is the density of the DCM maximum. Most data are from the upper 300m (density $<26.5$ ), while some nutrient data are from depths of up to $1000 \mathrm{~m}$ (density 27.3 ).

Figure 6. Plot of ${ }^{234} \mathrm{Th}$ flux $\left(\mathrm{dpm} \mathrm{m} \mathrm{m}^{-2} \mathrm{~d}^{-1}\right)$ vs. depth for the same stations as in Figure 3. The left panel shows flux results for $\mathrm{C} 1$ (black circle- E1 CTD 7; gray triangle- E2 CTD 8) and right panel for A4 (gray diamond- E3 CTD 18, black square- E4 CTD 5). Fluxes are shown with associated error bars appropriate to this 1D steady state model.

Figure 7. $\mathrm{POC} /{ }^{234} \mathrm{Th}$ ratios $\left(\mu \mathrm{mol} \mathrm{dpm}^{-1}\right)$ plotted for material collected via in situ pumping on filters with a $53 \mu \mathrm{m}$ nominal pore size. Data are plotted vs. pump cast \# for both $120 \mathrm{~m}$ samples 
(open symbols) and 150m (filled symbols). Cruise ID's are indicated on each panel. At the far right of the $\mathrm{X}$-axis on each plot, the $\mathrm{POC} /{ }^{234} \mathrm{Th}$ ratio for two separate sediment trap arrays are also shown as the larger gray filled symbols. The horizontal line is the average in each panel of the 120 and $150 \mathrm{~m}$ filter data.

Figure 8. POC flux (mmol $\mathrm{C} \mathrm{m}^{-2} \mathrm{~d}^{-1}$ ) plotted for each of the CTD stations sampled for ${ }^{234} \mathrm{Th}$ during EDDIES. Cruise ID's are indicated on each panel. The error bar is propagated from the uncertainty on the $1 \mathrm{D}$ steady state ${ }^{234} \mathrm{Th}$ flux model, and variability in POC/ ${ }^{234} \mathrm{Th}$ associated with the average values plotted in Figure 7 for the $>53 \mu \mathrm{m}$ particles. Station positions can be seen in Figure 1, and are provided along with sampling dates and flux data in Table 1. CTD's are sequential on each cruise, so the X-axis is essentially a time-series, and the central stations are noted by the filled symbols.

Figure 9. Sediment trap fluxes at $150 \mathrm{~m}$ are shown with each bar representing the concentration for an individual analysis conducted on a particular trap tube. All plots use the same vertical axis for flux of ${ }^{234} \mathrm{Th}$ (left; $\mathrm{dpm} \mathrm{m} \mathrm{m}^{-2} \mathrm{~d}^{-1}$ ), mass (right; $\mathrm{mg} \mathrm{m}^{-2} \mathrm{~d}^{-1}$ ) and POC (2nd right axis, mmol C m${ }^{-}$ ${ }^{2} \mathrm{~d}^{-1}$ ). During E1 and E2, traps were either in or out of the $\mathrm{C} 1$ eddy as indicated and discussed in the text. During E3 and E4, both traps were within eddy A4. Deployment periods were (start date \& duration): E1 IN- June 24, 2004, 3.44 d; E1 OUT- June 25, 3.50 d; E2 IN- Aug. 3, 5.76 d; E2 OUT (=BATS 190)- July 14, 2.62 d; E3A- July 8, 2005, 5.94 d; E3B- July 11, 3.72 d; E4AAug. 19, 6.17 d; Aug. 19, 5.17 d.

Figure 10 . The ${ }^{210} \mathrm{Po} /{ }^{210} \mathrm{~Pb}$ activity ratio measured on water samples collected from the A4 eddy. Note the persistent disequilibrium $\left({ }^{210} \mathrm{Po} /{ }^{210} \mathrm{~Pb}<1\right)$ throughout the top $500 \mathrm{~m}$ and which appeared at both the eddy center (EC) and edge stations $\left({ }^{210}\right.$ Po fluxes calculated in Table 2). Samples taken from the following CTD casts: E3 CTD 17 (EC) filled squares; E3 CTD 36 (edge) filled circles; E4 CTD 7 (EC) gray triangles; E4 CTD 26 (EC) inverted filled triangles.

Figure 11. A comparison of $150 \mathrm{~m}$ POC flux derived from the three methods used in EDDIES. For all cruises, the average POC flux with its standard deviation is shown for each cruise derived from ${ }^{234} \mathrm{Th}$ flux and the $\mathrm{POC} /{ }^{234} \mathrm{Th}$ ratio of the $>53 \mu \mathrm{m}$ filter (left gray bar) or $\mathrm{POC} /{ }^{234} \mathrm{Th}$ ratio of the $150 \mathrm{~m}$ trap (right gray hatched bar). Trap data (black bars) are shown separately as the average for the two trap arrays, with the standard deviation between replicate tubes shown as an error bar when available. ${ }^{210} \mathrm{Po}$-derived POC fluxes are available only for E3 and E4 and are provided for the two stations sampled, with the error bar representing the propagated error from the ${ }^{210} \mathrm{Po} /{ }^{210} \mathrm{~Pb}$ flux model and measured $\mathrm{POC} /{ }^{210} \mathrm{Po}$ ratio at that station. The horizontal dashed line is the average POC flux measured at BATS in $150 \mathrm{~m}$ traps for the summer period during 1988-2003, with the lower solid line for the 2004 and 2005 summer average. 
Table 1: Water sampling station information and thorium and ${ }^{234} \mathrm{Th}$ derived POC fluxes at $150 \mathrm{~m}$

\begin{tabular}{|c|c|c|c|c|c|c|c|c|}
\hline \multirow[b]{2}{*}{ CTD\# } & \multicolumn{2}{|c|}{ GMT } & \multirow{2}{*}{$\begin{array}{c}\text { Lat } \\
\mathbf{N}\end{array}$} & \multirow{2}{*}{$\begin{array}{c}\text { Long } \\
\text { W }\end{array}$} & \multirow{2}{*}{$\begin{array}{c}\text { Distance } \\
\text { km* }\end{array}$} & \multirow{2}{*}{$\begin{array}{c}{ }^{234} \text { Th flux }{ }^{\dagger} \pm \text { err } \\
\text { dpm } \mathbf{m}^{-2} \mathbf{d}^{-1}\end{array}$} & \multirow{2}{*}{$\begin{array}{l}\text { Pump derived } \\
\text { POC flux }{ }^{\dagger} \pm \text { err } \\
\text { mmol m}^{-2} \mathbf{d}^{-1}\end{array}$} & \multirow{2}{*}{$\begin{array}{c}\text { Trap derived } \\
\text { POC flux }{ }^{\dagger} \pm \text { range } \\
\text { mmol } \mathbf{m}^{-2} \mathbf{d}^{-1}\end{array}$} \\
\hline & Date & Time & & & & & & \\
\hline \multicolumn{9}{|c|}{ Cruise E1 ${ }^{a}$} \\
\hline $1^{*}$ & 24-Jun-04 & $13: 41$ & 30.458 & 64.893 & 16.2 & $552 \pm 136$ & $2.2 \pm 0.6$ & $1.9 \pm 0.8$ \\
\hline 4 & 25-Jun-04 & $15: 05$ & 31.219 & 64.082 & 99.5 & $1045 \pm 171$ & $4.1 \pm 0.9$ & $3.6 \pm 1.4$ \\
\hline 5 & 25-Jun-04 & 20:07 & 30.860 & 64.503 & 51.8 & $1234 \pm 145$ & $4.9 \pm 0.9$ & $4.3 \pm 1.6$ \\
\hline 6 & 26-Jun-04 & $2: 04$ & 30.681 & 64.713 & 32.1 & $1307 \pm 126$ & $5.2 \pm 0.9$ & $4.5 \pm 1.6$ \\
\hline $7^{*}$ & 26-Jun-04 & $9: 12$ & 30.500 & 64.923 & 16.6 & $1163 \pm 139$ & $4.6 \pm 0.8$ & $4.0 \pm 1.5$ \\
\hline $8 *$ & 26-Jun-04 & $16: 53$ & 30.321 & 65.128 & 22.2 & $1225 \pm 124$ & $4.8 \pm 0.8$ & $4.3 \pm 1.5$ \\
\hline 9 & 26-Jun-04 & $22: 20$ & 30.146 & 65.337 & 48.3 & $1389 \pm 143$ & $5.5 \pm 0.9$ & $4.8 \pm 1.7$ \\
\hline 10 & 27-Jun-04 & $5: 51$ & 29.779 & 65.760 & 106.5 & $1309 \pm 142$ & $5.2 \pm 0.9$ & $4.5 \pm 1.6$ \\
\hline 11 & 27-Jun-04 & $10: 57$ & 30.163 & 65.341 & 50.1 & $1349 \pm 119$ & $5.3 \pm 0.9$ & $4.7 \pm 1.7$ \\
\hline 12 & 27-Jun-04 & $16: 03$ & 30.323 & 65.132 & 27.5 & $951 \pm 130$ & $3.8 \pm 0.7$ & $3.3 \pm 1.2$ \\
\hline 13 & 27-Jun-04 & $22: 15$ & 30.681 & 64.711 & 36.1 & $755 \pm 118$ & $3.0 \pm 0.6$ & $2.6 \pm 1.0$ \\
\hline 14 & 28-Jun-04 & $8: 36$ & 30.861 & 64.502 & 60.2 & $1091 \pm 134$ & $4.3 \pm 0.8$ & $3.8 \pm 1.4$ \\
\hline 15 & 28-Jun-04 & $17: 05$ & 31.218 & 64.084 & 114.0 & $844 \pm 122$ & $3.3 \pm 0.7$ & $2.9 \pm 1.1$ \\
\hline $17^{*}$ & 29-Jun-04 & 14:04 & 30.500 & 64.920 & 14.5 & $156 \pm 284$ & $0.6 \pm 1.1$ & $0.5 \pm 1.0$ \\
\hline 19 & 30-Jun-04 & $13: 33$ & 29.959 & 65.551 & 80.3 & $764 \pm 117$ & $3.0 \pm 0.6$ & $2.7 \pm 1.0$ \\
\hline 23 & 30-Jun-04 & $22: 17$ & 29.783 & 66.178 & 132.2 & $1568 \pm 168$ & $6.2 \pm 1.1$ & $5.4 \pm 2.0$ \\
\hline \multirow[t]{2}{*}{$27^{\ddagger}$} & 2-Jul-04 & $1: 45$ & 30.494 & 65.129 & 10.4 & $1759 \pm 129$ & $7.0 \pm 1.1$ & $6.1 \pm 2.2$ \\
\hline & & & & \multicolumn{2}{|c|}{ average \pm std dev } & $1086 \pm 390$ & $4.3 \pm 1.5$ & $3.8 \pm 1.4$ \\
\hline
\end{tabular}

Cruise E2 ${ }^{b}$

\begin{tabular}{|c|c|c|c|c|c|c|c|}
\hline 102 -Aug-04 & $21: 21$ & 31.667 & 64.164 & 175.2 & $782 \pm 112$ & $1.7 \pm 0.7$ & $3.2 \pm 0.5$ \\
\hline 4 04-Aug-04 & $1: 48$ & 30.667 & 65.547 & 23.9 & $1026 \pm 140$ & $2.3 \pm 0.9$ & $4.2 \pm 0.6$ \\
\hline 5 04-Aug-04 & $8: 42$ & 30.682 & 65.335 & 43.4 & $666 \pm 112$ & $1.5 \pm 0.6$ & $2.7 \pm 0.5$ \\
\hline 6/7*04-Aug-04 & 14:05 & 30.679 & 65.751 & 15.4 & $981 \pm 105$ & $2.2 \pm 0.8$ & $4.0 \pm 0.5$ \\
\hline $8^{\ddagger}$ 04-Aug-04 & $22: 05$ & 30.859 & 65.762 & 6.4 & $698 \pm 124$ & $1.5 \pm 0.6$ & $2.8 \pm 0.5$ \\
\hline 9 05-Aug-04 & $3: 23$ & 31.040 & 65.761 & 26.1 & $570 \pm 108$ & $1.3 \pm 0.5$ & $2.3 \pm 0.5$ \\
\hline 10 05-Aug-04 & $10: 15$ & 31.403 & 65.763 & 66.6 & $905 \pm 120$ & $2.0 \pm 0.8$ & $3.7 \pm 0.6$ \\
\hline 11 05-Aug-04 & $16: 41$ & 31.761 & 65.760 & 107.1 & $347 \pm 107$ & $0.8 \pm 0.4$ & $1.4 \pm 0.4$ \\
\hline $15^{*} 06$-Aug-04 & $13: 47$ & 30.861 & 65.762 & 16.0 & $1191 \pm 111$ & $2.6 \pm 1.0$ & $4.8 \pm 0.6$ \\
\hline 17 09-Aug-04 & $14: 51$ & 30.331 & 65.789 & 58.8 & $890 \pm 110$ & $2.0 \pm 0.7$ & $3.6 \pm 0.5$ \\
\hline 18 09-Aug-04 & $19: 55$ & 30.491 & 65.765 & 45.0 & $235 \pm 99$ & $0.5 \pm 0.3$ & $1.0 \pm 0.4$ \\
\hline & & & avera & $\pm s t d d \epsilon$ & $754 \pm 406$ & $1.7 \pm 0.6$ & $3.1 \pm 1.2$ \\
\hline
\end{tabular}

Cruise E3 ${ }^{c}$

$\begin{array}{rrrrrrrrr}\text { 1/BATS } & \text { 6-Jul-05 } & 22: 50 & 31.669 & 64.168 & 223.3 & 1300 \pm 151 & 3.2 \pm 0.6 & 4.4 \pm 0.6 \\ 2^{\ddagger} & \text { 7-Jul-05 } & 12: 40 & 30.902 & 66.289 & 9.1 & 563 \pm 166 & 1.4 \pm 0.5 & 1.9 \pm 0.6 \\ 4 & \text { 7-Jul-05 } & 21: 39 & 31.065 & 66.292 & 27.1 & 280 \pm 178 & 0.7 \pm 0.5 & 0.9 \pm 0.6 \\ 9^{\ddagger} & \text { 8-Jul-05 } & 16: 28 & 30.896 & 66.285 & 17.5 & 436 \pm 233 & 1.1 \pm 0.6 & 1.5 \pm 0.8 \\ 10 & \text { 9-Jul-05 } & 8: 50 & 30.901 & 65.623 & 99.6 & 1224 \pm 159 & 3.1 \pm 0.6 & 4.1 \pm 0.6 \\ 11 & \text { 9-Jul-05 } & 12: 54 & 30.903 & 65.873 & 61.2 & 522 \pm 170 & 1.3 \pm 0.5 & 1.7 \pm 0.6 \\ 12 & \text { 9-Jul-05 } & 19: 40 & 30.902 & 66.083 & 42.8 & 167 \pm 203 & 0.4 \pm 0.5 & 0.6 \pm 0.7 \\ 17^{\ddagger} & \text { 10-Jul-05 } & 9: 35 & 30.901 & 66.497 & 12.8 & 253 \pm 154 & 0.6 \pm 0.4 & 0.8 \pm 0.5 \\ 18^{\ddagger} & \text { 10-Jul-05 } & 13: 16 & 30.903 & 66.705 & 19.6 & 620 \pm 195 & 1.5 \pm 0.5 & 2.1 \pm 0.7\end{array}$


Table 1 cont.

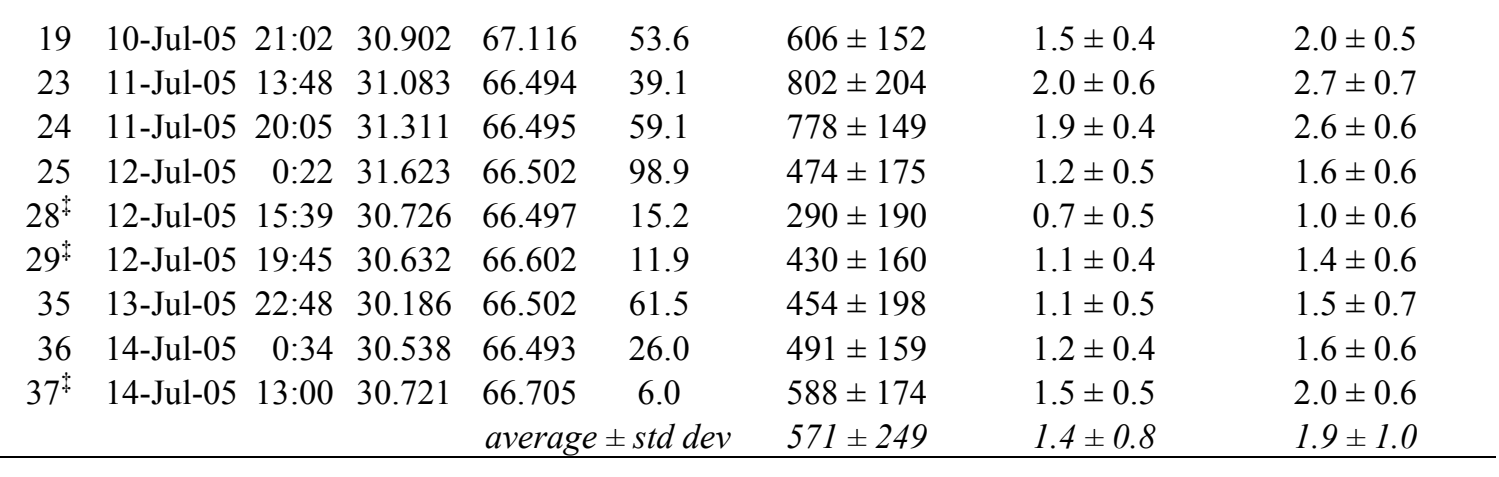

\begin{tabular}{|c|c|c|c|c|c|c|}
\hline \\
\hline \multicolumn{7}{|c|}{$\begin{array}{r}\text { Crulse } \\
\qquad 1^{\ddagger} \text { 18-Aug-05 }\end{array} 21: 10 \quad 30.181 \quad 68.643$} \\
\hline $5^{\ddagger}$ 19-Aug-05 16:00 & 30.184 & 68.674 & 11.9 & $689 \pm 155$ & $1.3 \pm 0.6$ & $1.2 \pm 0.4$ \\
\hline $7^{\ddagger} 20$-Aug-05 $2: 25$ & 30.180 & 68.576 & 14.5 & $618 \pm 178$ & $1.2 \pm 0.6$ & $1.1 \pm 0.4$ \\
\hline 10 20-Aug-05 14:07 & 30.179 & 69.409 & 72.5 & $1184 \pm 141$ & $2.3 \pm 1.0$ & $2.0 \pm 0.5$ \\
\hline 11 20-Aug-05 22:19 & 30.180 & 68.993 & 32.5 & $979 \pm 186$ & $1.9 \pm 0.9$ & $1.7 \pm 0.5$ \\
\hline $12 * 21$-Aug-05 $1: 50$ & 30.180 & 68.785 & 16.3 & $1103 \pm 193$ & $2.1 \pm 1.0$ & $1.9 \pm 0.6$ \\
\hline 15 21-Aug-05 15:32 & 30.179 & 68.368 & 36.3 & $515 \pm 225$ & $1.0 \pm 0.6$ & $0.9 \pm 0.4$ \\
\hline 16 21-Aug-05 21:40 & 30.178 & 68.155 & 57.8 & $1114 \pm 192$ & $2.1 \pm 1.0$ & $1.9 \pm 0.6$ \\
\hline 17 22-Aug-05 2:05 & 30.178 & 67.750 & 98.8 & $906 \pm 198$ & $1.7 \pm 0.8$ & $1.6 \pm 0.5$ \\
\hline $20^{\ddagger} 22$-Aug-05 $16: 58$ & 30.004 & 68.789 & 1.9 & $669 \pm 381$ & $1.3 \pm 0.9$ & $1.2 \pm 0.7$ \\
\hline $23^{*} 23$-Aug-05 $\quad 0: 52$ & 30.089 & 68.680 & 18.6 & $969 \pm 174$ & $1.9 \pm 0.9$ & $1.7 \pm 0.5$ \\
\hline $26^{\ddagger} 23$-Aug-05 $18: 25$ & 29.947 & 68.976 & 7.6 & $311 \pm 188$ & $0.6 \pm 0.4$ & $0.5 \pm 0.3$ \\
\hline $31^{\ddagger} 24$-Aug-05 $11: 58$ & 29.906 & 69.107 & 18.8 & $311 \pm 188$ & $0.6 \pm 0.4$ & $0.5 \pm 0.3$ \\
\hline $32 * 24$-Aug-05 19:26 & 29.811 & 68.995 & 17.1 & $841 \pm 190$ & $1.6 \pm 0.8$ & $1.5 \pm 0.5$ \\
\hline $34: 25$-Aug-05 $\quad 0: 15$ & 30.003 & 68.981 & 4.3 & $698 \pm 213$ & $1.3 \pm 0.7$ & $1.2 \pm 0.5$ \\
\hline $37^{\ddagger} 25$-Aug-05 $9: 55$ & 29.914 & 69.191 & 16.4 & $181 \pm 150$ & $0.3 \pm 0.3$ & $0.3 \pm 0.3$ \\
\hline $38^{\ddagger} 25$-Aug-05 $12: 38$ & 30.003 & 69.175 & 17.0 & $0 \pm 190$ & & \\
\hline $39^{\ddagger} 25$-Aug-05 $17: 15$ & 29.875 & 68.880 & 16.9 & $434 \pm 219$ & $0.8 \pm 0.5$ & $0.8 \pm 0.4$ \\
\hline & & average & std dev & $681 \pm 349$ & $1.4 \pm 0.6$ & $1.2 \pm 0.5$ \\
\hline
\end{tabular}

* distance from eddy center

${ }^{\dagger}$ All POC fluxes calculated for $150 \mathrm{~m}$.

${ }^{\ddagger}$ Central stations defined as those that are $<25 \mathrm{~km}$ from eddy center

Particulate ratios at $120-150 \mathrm{~m}$ as used for POC flux calculations. Fluxes of bSi and PON can be calculated from ratios provided here and ${ }^{234} \mathrm{Th}$ flux data for each cruise as listed in this Table.

${ }^{\mathrm{a}} \mathrm{E} 1>53 \mu \mathrm{m}$ pump: $\mathrm{POC} /{ }^{234} \mathrm{Th}=4.0 \pm 0.5 ; \mathrm{bSi}{ }^{234} \mathrm{Th}=0.11 \pm 0.05$

Trap: $\mathrm{POC} /{ }^{234} \mathrm{Th}=3.5 \pm 1.2 ; \mathrm{C} / \mathrm{N}=8.2 \pm 0.9$

${ }^{\mathrm{b}} \mathrm{E} 2>53 \mu \mathrm{m}$ pump: $\mathrm{POC} /{ }^{234} \mathrm{Th}=2.2 \pm 0.8 ; \mathrm{bSi} /{ }^{234} \mathrm{Th}=0.20 \pm 0.11$

Trap: $\mathrm{POC} /{ }^{234} \mathrm{Th}=4.1 \pm 0.3 ; \mathrm{C} / \mathrm{N}=7.9 \pm 0.6$

${ }^{\mathrm{c}} \mathrm{E} 3>53 \mu \mathrm{m}$ pump: $\mathrm{POC} /{ }^{234} \mathrm{Th}=2.5 \pm 0.3 ; \mathrm{bSi} /{ }^{234} \mathrm{Th}=0.11 \pm 0.01$ (non-central), $0.35 \pm 0.07$ (central)

Trap: $\mathrm{POC} /{ }^{234} \mathrm{Th}=3.4 \pm 0.3 ; \mathrm{C} / \mathrm{N}=7.8 \pm 0.7$

${ }^{\mathrm{d}} \mathrm{E} 4>53 \mu \mathrm{m}$ pump: $\mathrm{POC}{ }^{234} \mathrm{Th}=1.9 \pm 0.8 ; \mathrm{bSi} /{ }^{234} \mathrm{Th}=0.15 \pm 0.06$ (non-central), $0.27 \pm 0.05$ (central)

Trap: $\mathrm{POC} /{ }^{234} \mathrm{Th}=1.7 \pm 0.4 ; \mathrm{C} / \mathrm{N}=6.9 \pm 0.5$ 
Table 2: Summary of pump cast station information

\begin{tabular}{|c|c|c|c|c|c|}
\hline \multirow{2}{*}{$\begin{array}{l}\text { Pump } \\
\text { cast \# }\end{array}$} & \multicolumn{2}{|c|}{ GMT } & \multirow{2}{*}{$\begin{array}{c}\text { Lat } \\
\mathbf{N}\end{array}$} & \multirow{2}{*}{$\begin{array}{c}\text { Long } \\
\text { W }\end{array}$} & \multirow{2}{*}{$\begin{array}{l}\text { Closes } \\
\text { CTD\# }\end{array}$} \\
\hline & Date & Time & & & \\
\hline \multicolumn{6}{|c|}{ Cruise E1 } \\
\hline 1 & 24-Jun-04 & $19: 30$ & 30.458 & 64.893 & 1 \\
\hline 2 & 25-Jun-04 & $11: 00$ & 31.219 & 64.082 & 4 \\
\hline 3 & 25-Jun-04 & 00:0 & 30.86 & 64.503 & 5 \\
\hline 4 & 26-Jun-04 & $22: 00$ & 30.146 & 65.337 & 9 \\
\hline 5 & 27-Jun-04 & $05: 20$ & 29.779 & 65.76 & 10 \\
\hline 6 & 28-Jun-04 & 04:00 & 30.861 & 64.502 & 14 \\
\hline 7 & 28-Jun-04 & $15: 40$ & 31.218 & 64.084 & 15 \\
\hline 8 & 29-Jun-04 & $13: 00$ & 30.5 & 64.92 & 17 \\
\hline 9 & 30-Jun-04 & $07: 15$ & 29.878 & 65.129 & 23 \\
\hline \multicolumn{6}{|c|}{ Cruise E2 } \\
\hline 1 & 03-Aug-04 & $13: 10$ & 30.68 & 65.547 & 4 \\
\hline 2 & 04-Aug-04 & $13: 45$ & 30.679 & 65.751 & 6 \\
\hline 3 & 04-Aug-04 & $21: 45$ & 31.04 & 65.761 & 9 \\
\hline & 05-Aug-04 & $07: 40$ & 31.403 & 65.763 & 10 \\
\hline 5 & 05-Aug-04 & $11: 20$ & 31.761 & 65.76 & 11 \\
\hline 6 & 06-Aug-04 & 08:00 & 30.861 & 65.762 & 15 \\
\hline 7 & 06-Aug-04 & $15: 00$ & 30.672 & 65.736 & 15 \\
\hline 8 & 09-Aug-04 & 09:30 & 30.331 & 65.789 & 17 \\
\hline \multicolumn{6}{|c|}{ Cruise E3 } \\
\hline 1 & 08-Jul-05 & $16: 28$ & 30.896 & 66.285 & 9 \\
\hline 2 & 09-Jul-05 & $08: 50$ & 30.901 & 65.623 & 10 \\
\hline 3 & 09-Jul-05 & $19: 40$ & 30.902 & 66.083 & 12 \\
\hline 4 & 10-Jul-05 & 09:35 & 30.901 & 66.497 & 17 \\
\hline 5 & 10-Jul-05 & $21: 02$ & 30.902 & 67.116 & 19 \\
\hline 6 & 11-Jul-05 & $13: 48$ & 31.083 & 66.494 & 23 \\
\hline 7 & 12-Jul-05 & $15: 39$ & 30.726 & 66.497 & 28 \\
\hline 8 & 14-Jul-05 & $00: 34$ & 30.538 & 66.493 & 36 \\
\hline \multicolumn{6}{|c|}{ Cruise E4 } \\
\hline 1 & 20-Aug-05 & $02: 25$ & 30.18 & 68.58 & 7 \\
\hline 2 & 20-Aug-05 & $14: 07$ & 30.18 & 69.41 & 10 \\
\hline 3 & 21-Aug-05 & $01: 50$ & 30.18 & 68.78 & 12 \\
\hline 4 & 21-Aug-05 & $15: 32$ & 30.18 & 68.37 & 15 \\
\hline 5 & 22-Aug-05 & 02:05 & 30.18 & 67.75 & 17 \\
\hline 6 & 23-Aug-05 & $18: 25$ & 29.95 & 68.98 & 26 \\
\hline 7 & 24-Aug-05 & $11: 58$ & 29.91 & 69.11 & 31 \\
\hline 8 & 25 -Aug- 05 & $17: 15$ & 29.88 & 68.88 & 39 \\
\hline
\end{tabular}


Table 3: ${ }^{210}$ Po flux and ${ }^{210}$ Po derived POC fluxes at $150 \mathrm{~m}$

\begin{tabular}{|c|c|c|c|}
\hline CTD \# & Date & $\begin{array}{l}{ }^{210} \text { Po flux }{ }^{\dagger} \pm \text { err } \\
\text { dpm m }{ }^{-2} d^{-1}\end{array}$ & $\begin{array}{l}\text { POC flux }{ }^{\dagger} \pm \text { err } \\
\text { mmol m }^{-2} \mathbf{d}^{-1}\end{array}$ \\
\hline \multicolumn{4}{|l|}{ Cruise E3 } \\
\hline 17 & 10-Jul-05 & $78.5 \pm 9.1$ & $4.5 \pm 2.4$ \\
\hline 36 & 14-Jul-05 & $93.2 \pm 3.5$ & $3.5 \pm 1.1$ \\
\hline \multicolumn{4}{|c|}{ Cruise E4 } \\
\hline 7 & 20-Aug-05 & $37.8 \pm 3.7$ & $3.3 \pm 1.1$ \\
\hline 26 & 23-Aug-05 & $57.5 \pm 4.2$ & $1.5 \pm 0.5$ \\
\hline
\end{tabular}

${ }^{\dagger}$ All fluxes calculated for $150 \mathrm{~m}$. 
Figure 1 Buesseler et al. DSRII
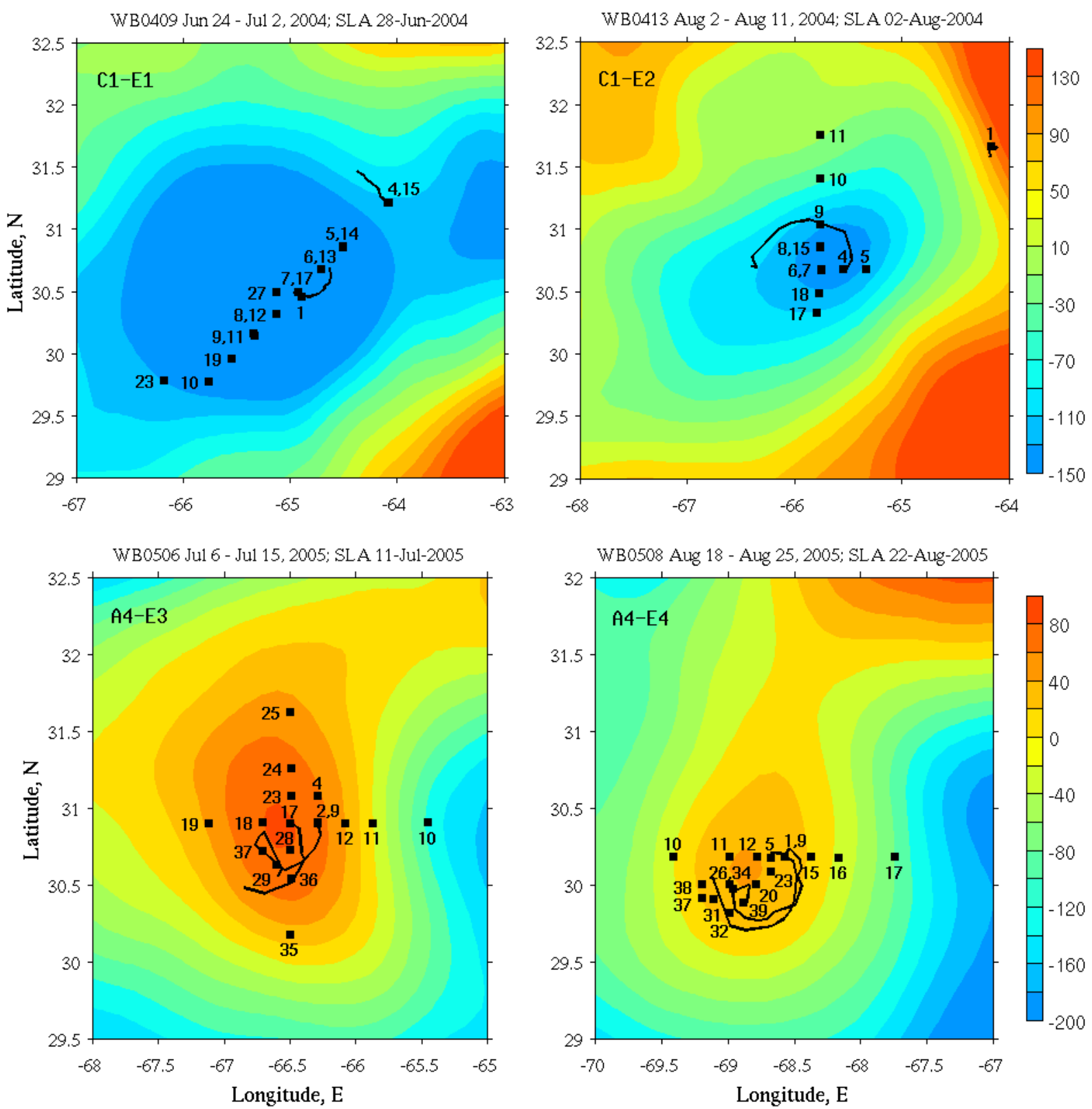
Figure 2. Buesseler et al. DSRII

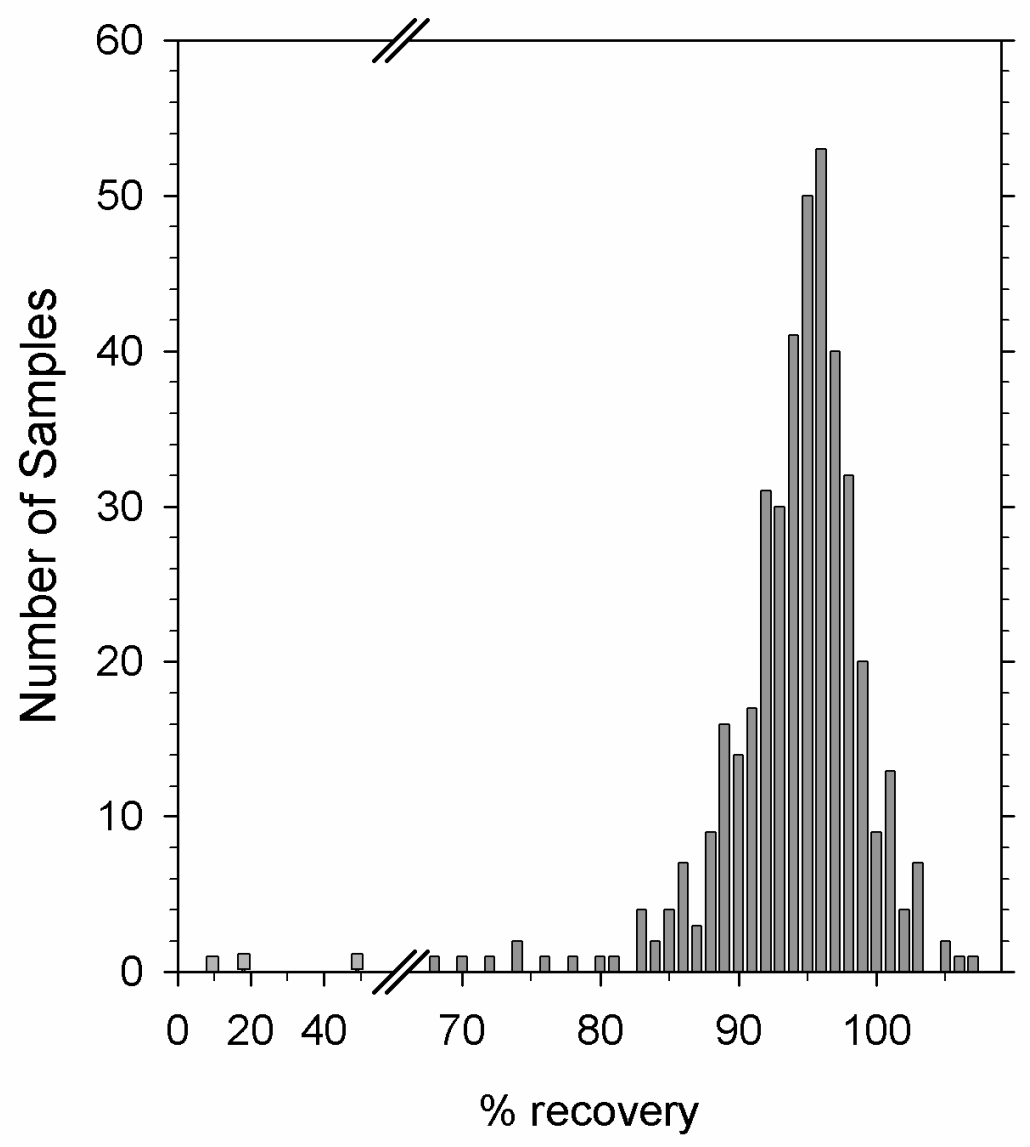


Figure 3. Buesseler et al. DSRII
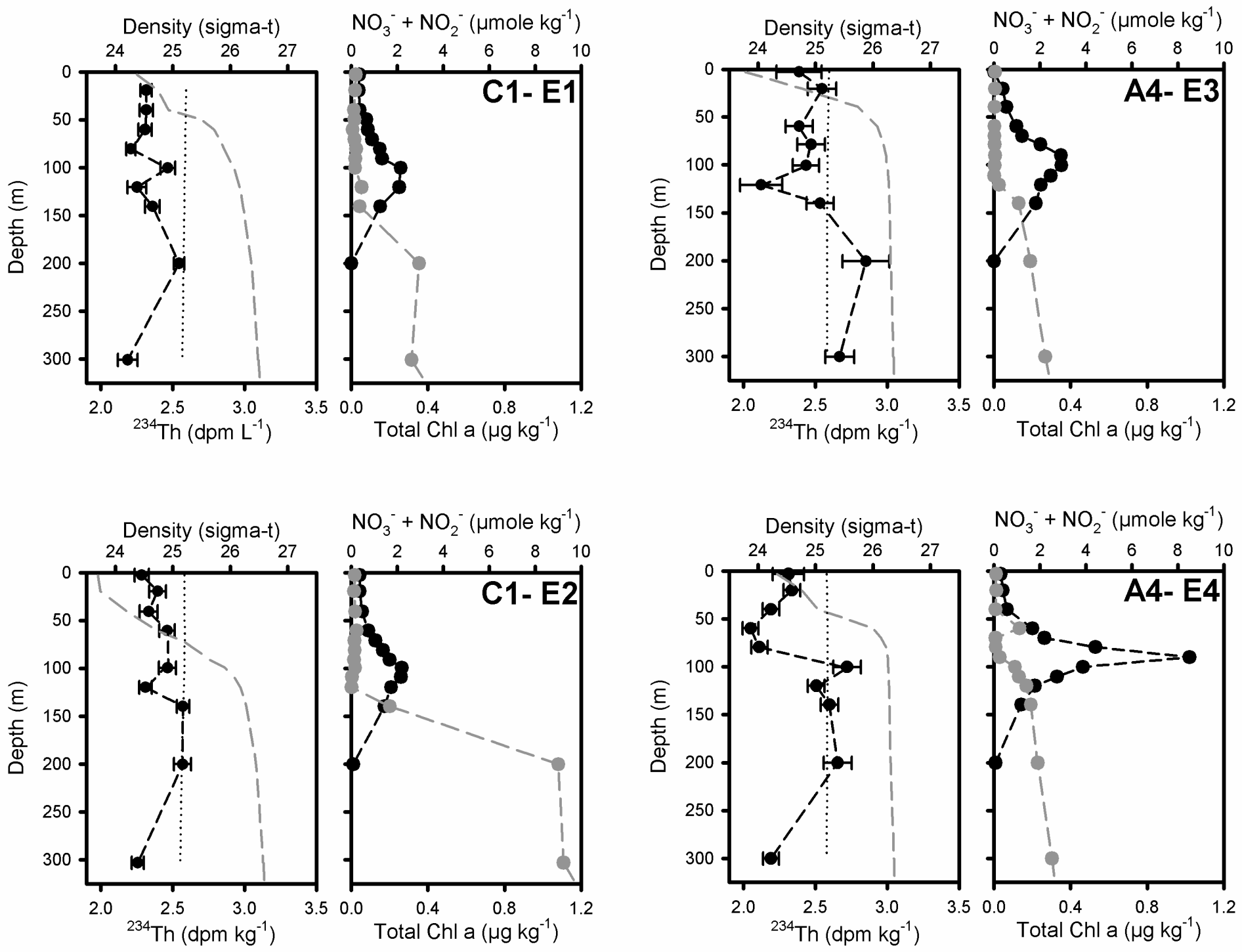
Figure 4 Buesseler et al. DSRII
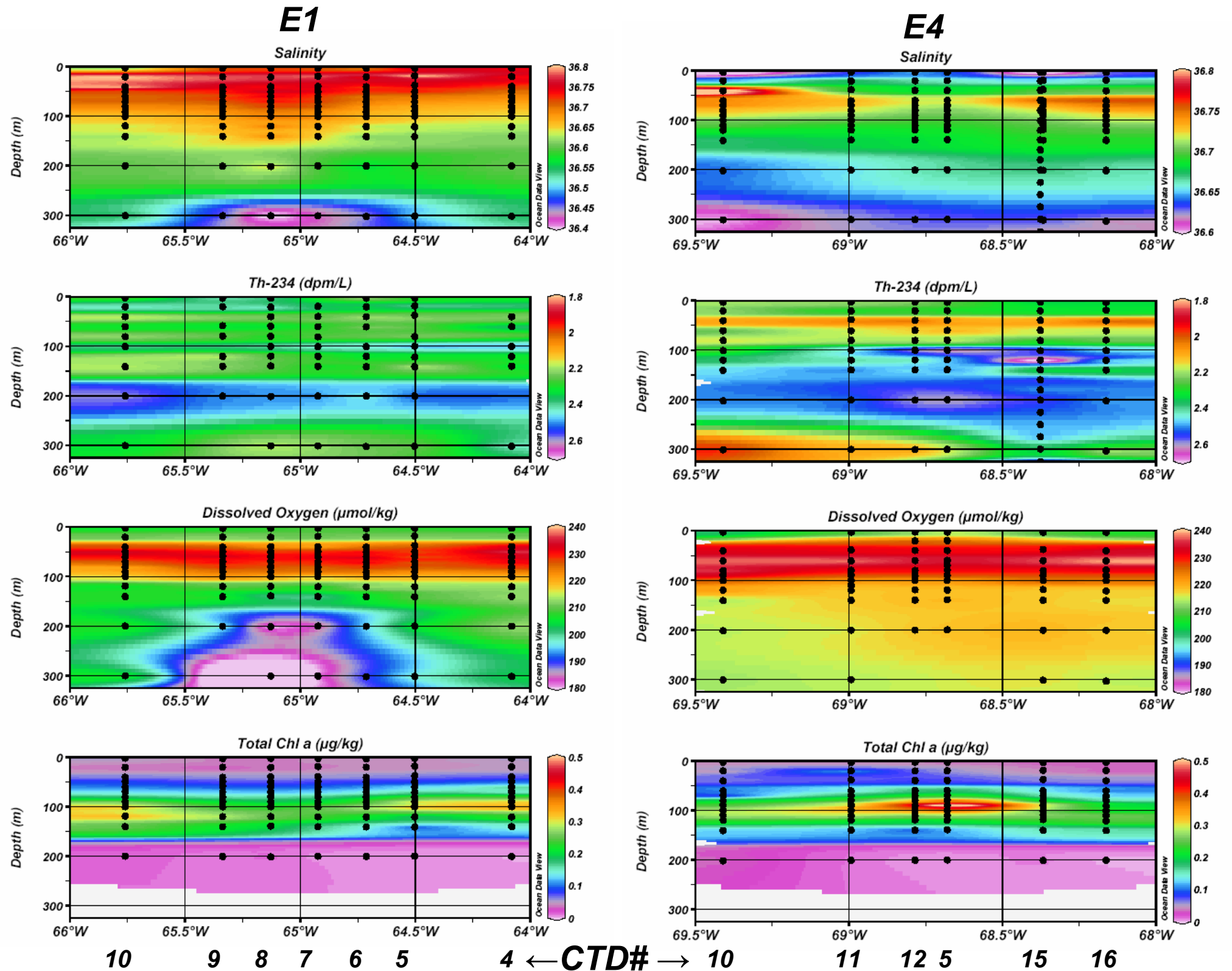
Fig 5a. Buesseler et al. DSRII
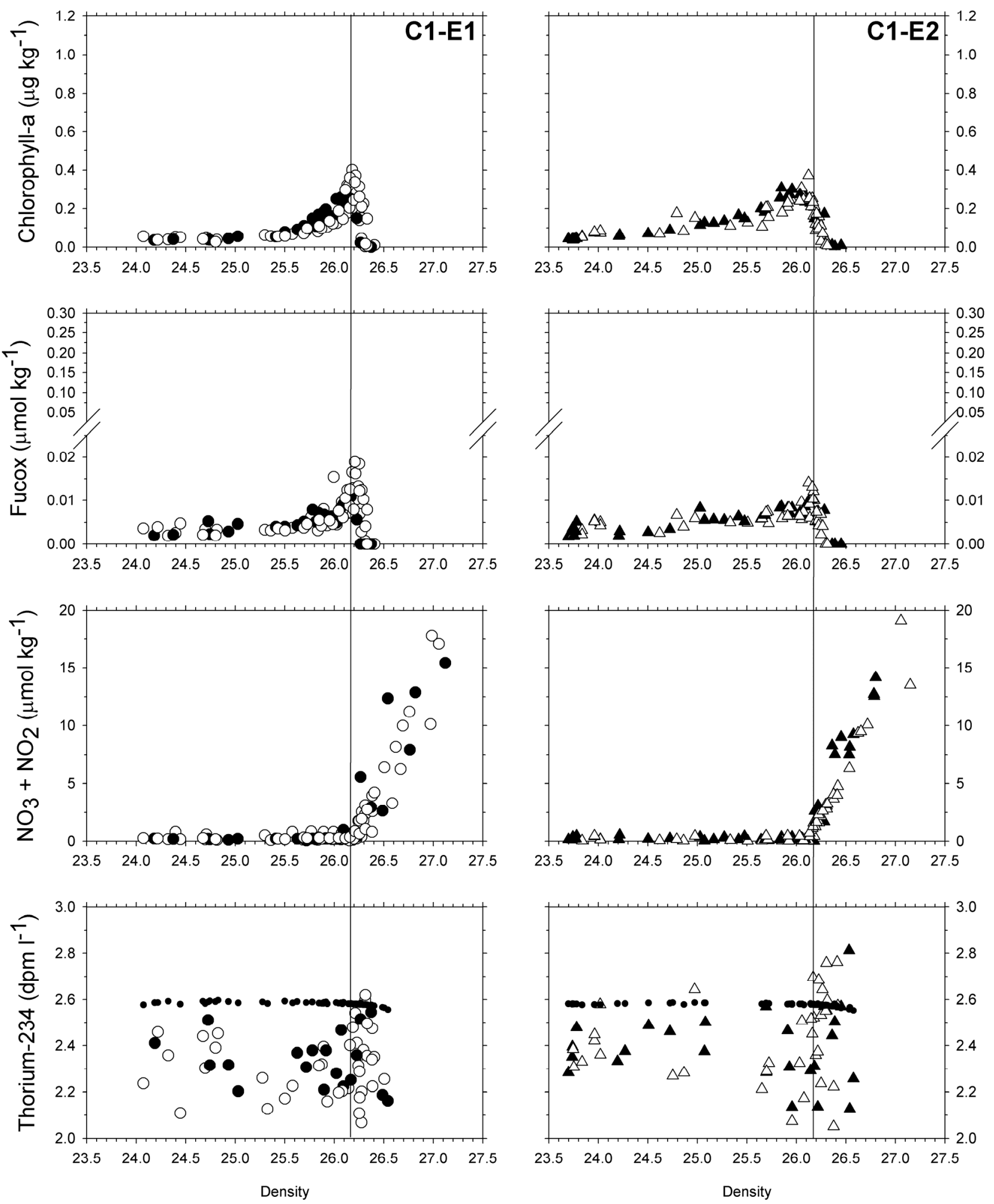
Fig 5b. Buesseler et al. DSRII
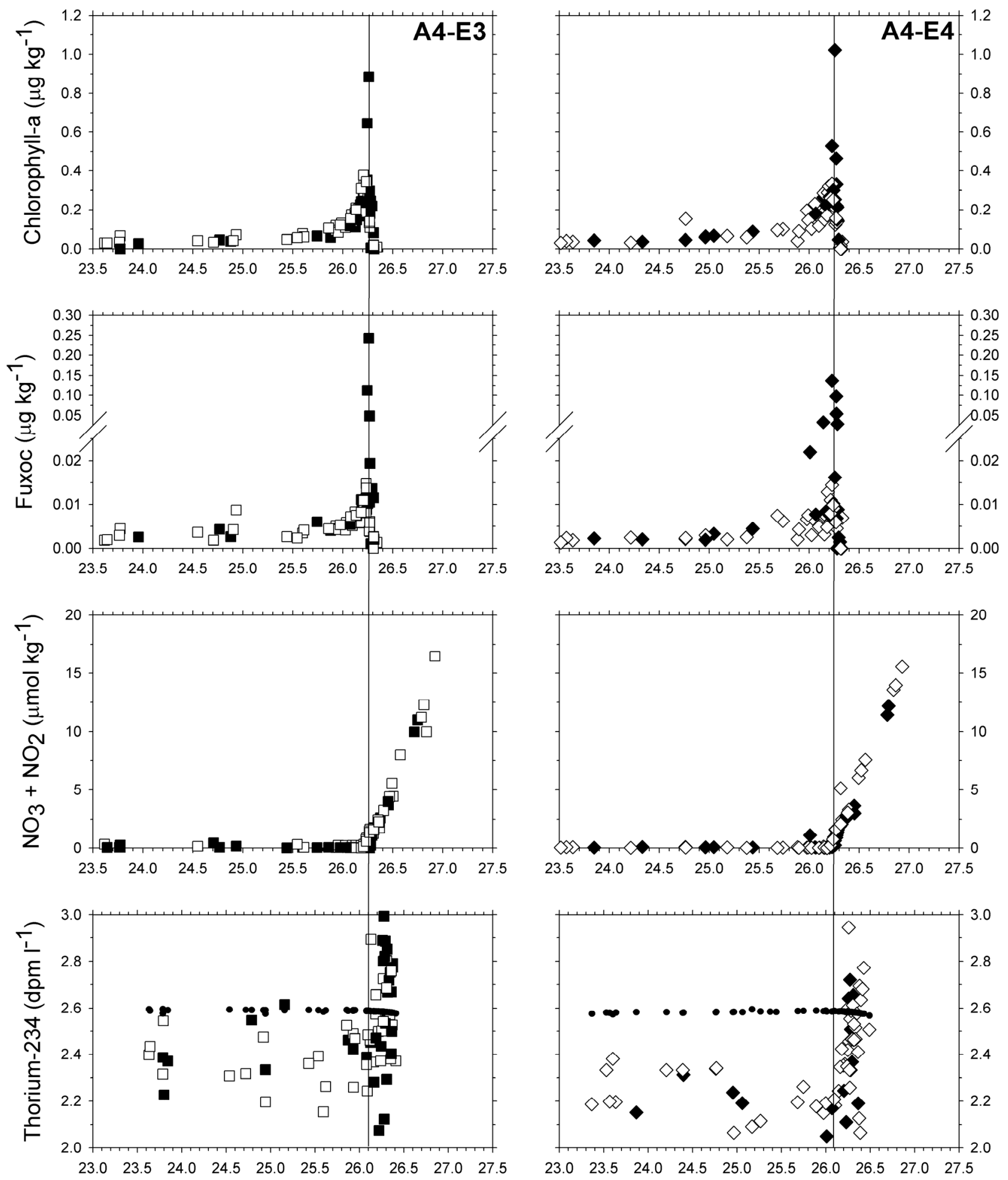

Density

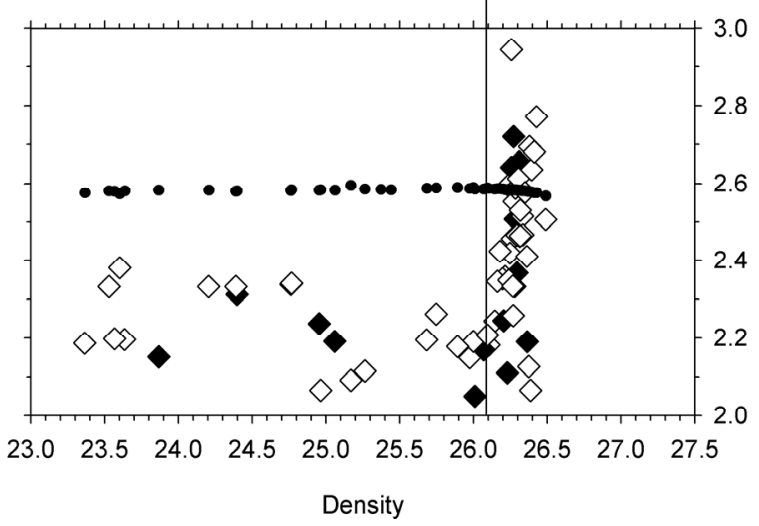


Figure 6. Buesseler et al. DSRII

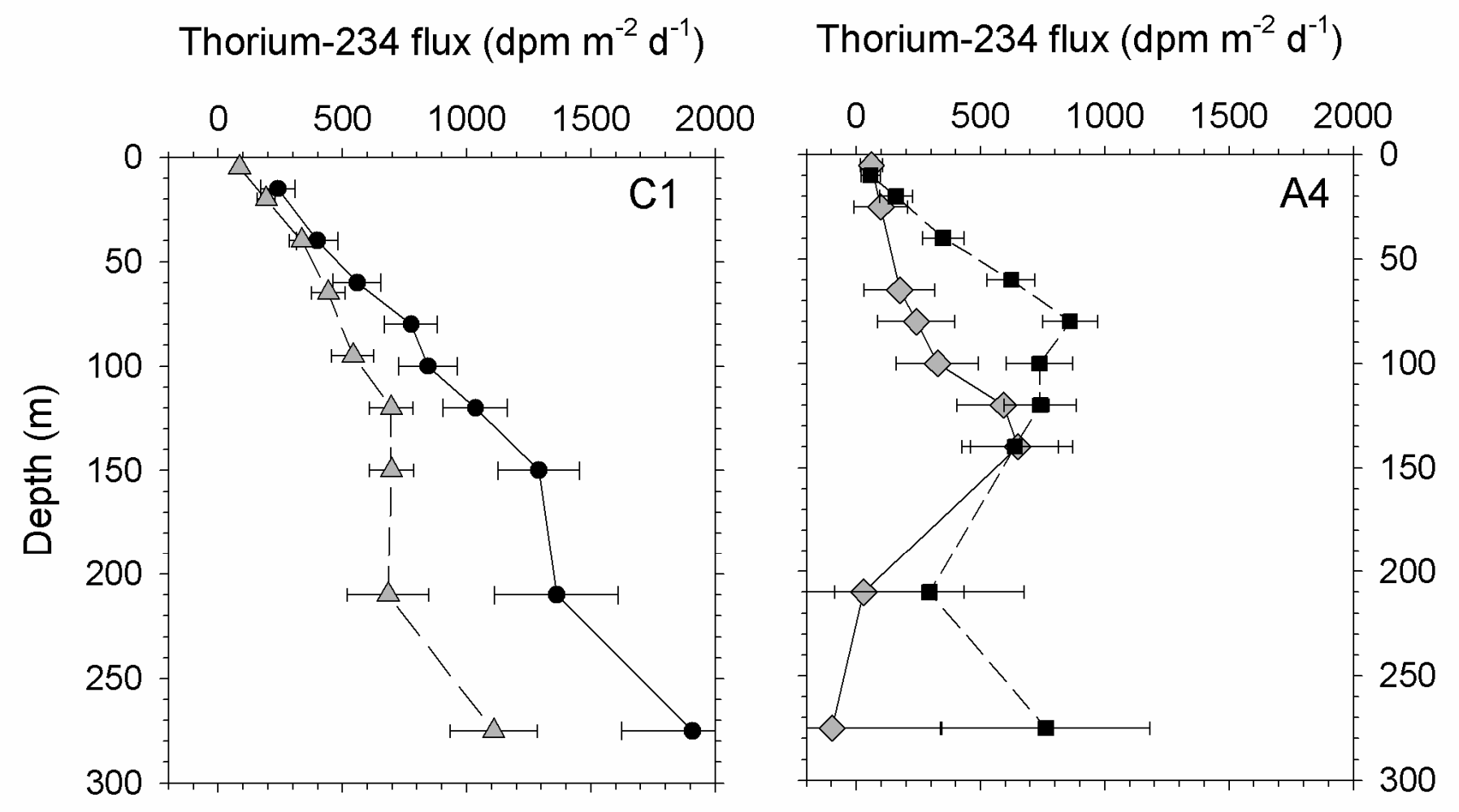


Figure 7 Buesseler et al. DSRII
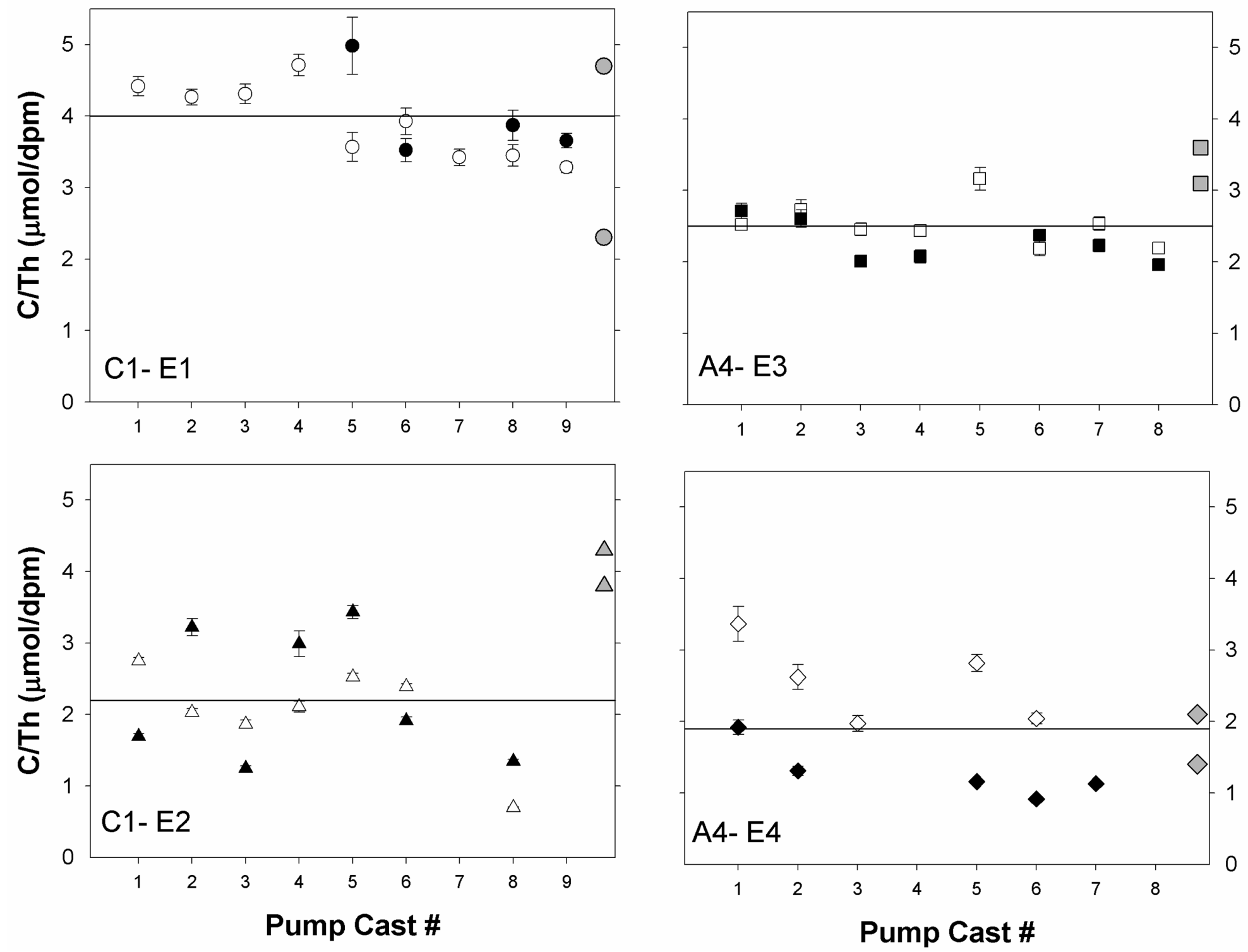
Figure 8. Buesseler et al. DSRII
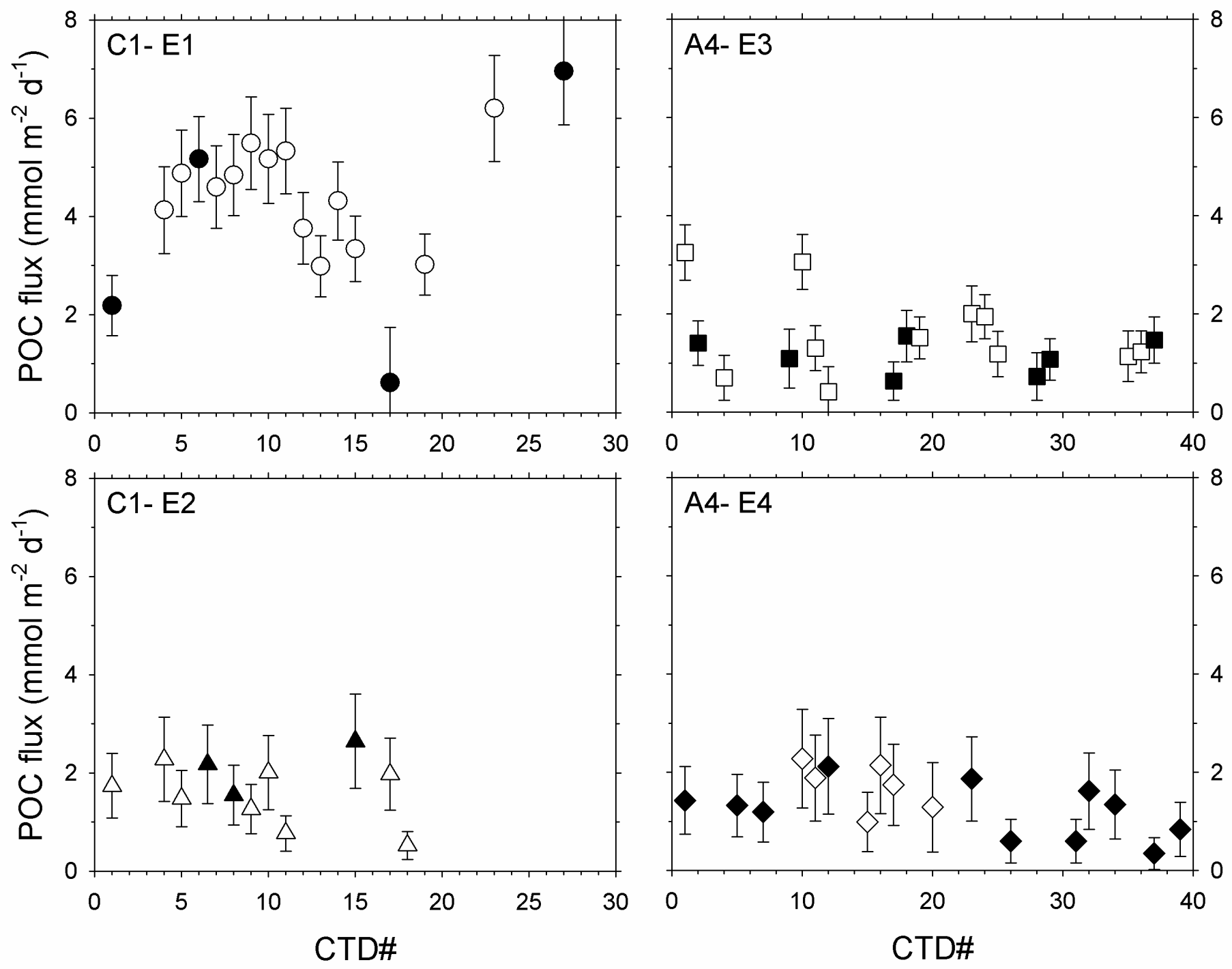
Figure 9 Buesseler et al. DSRII
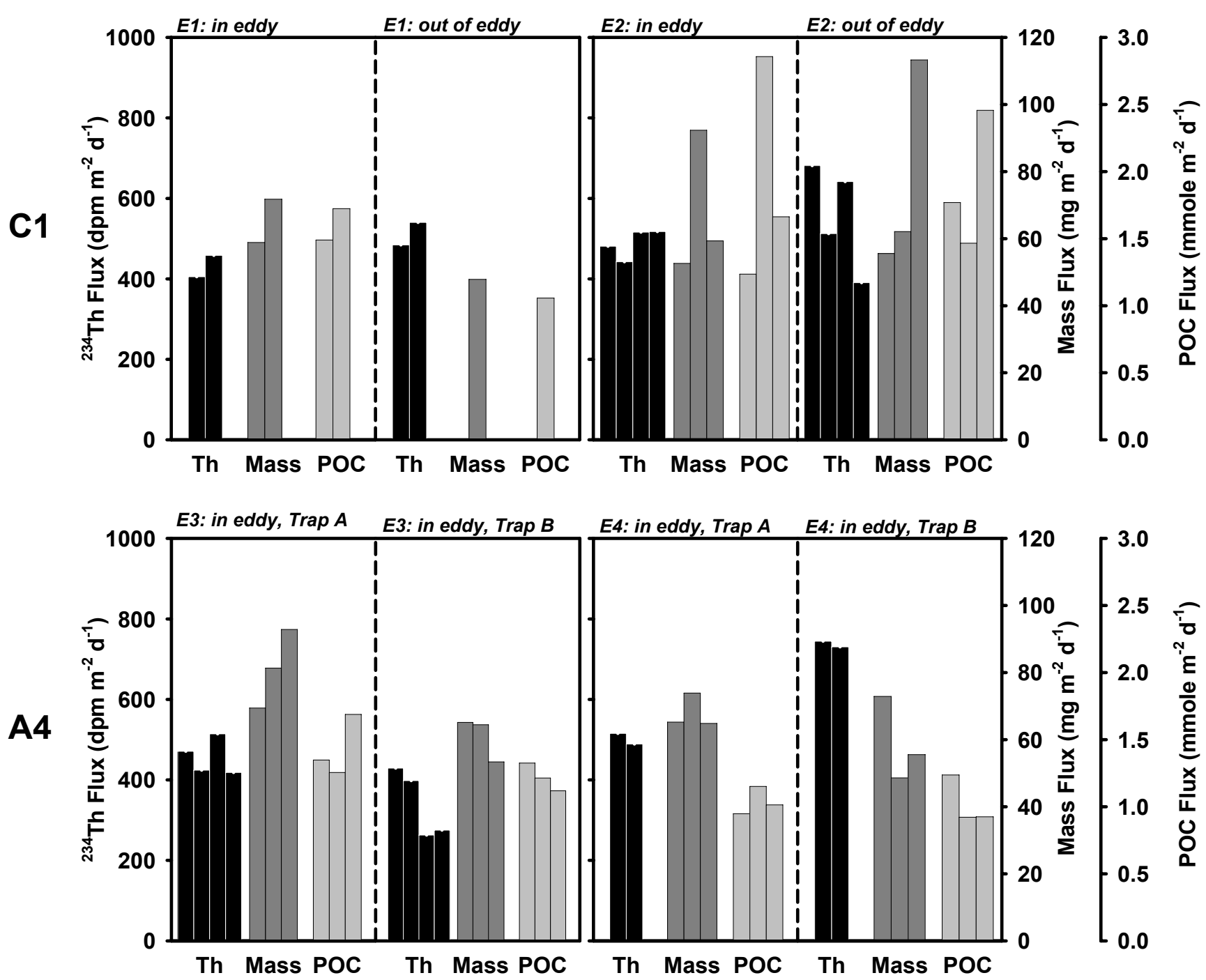
Figure 10. Buesseler et al. DSRII

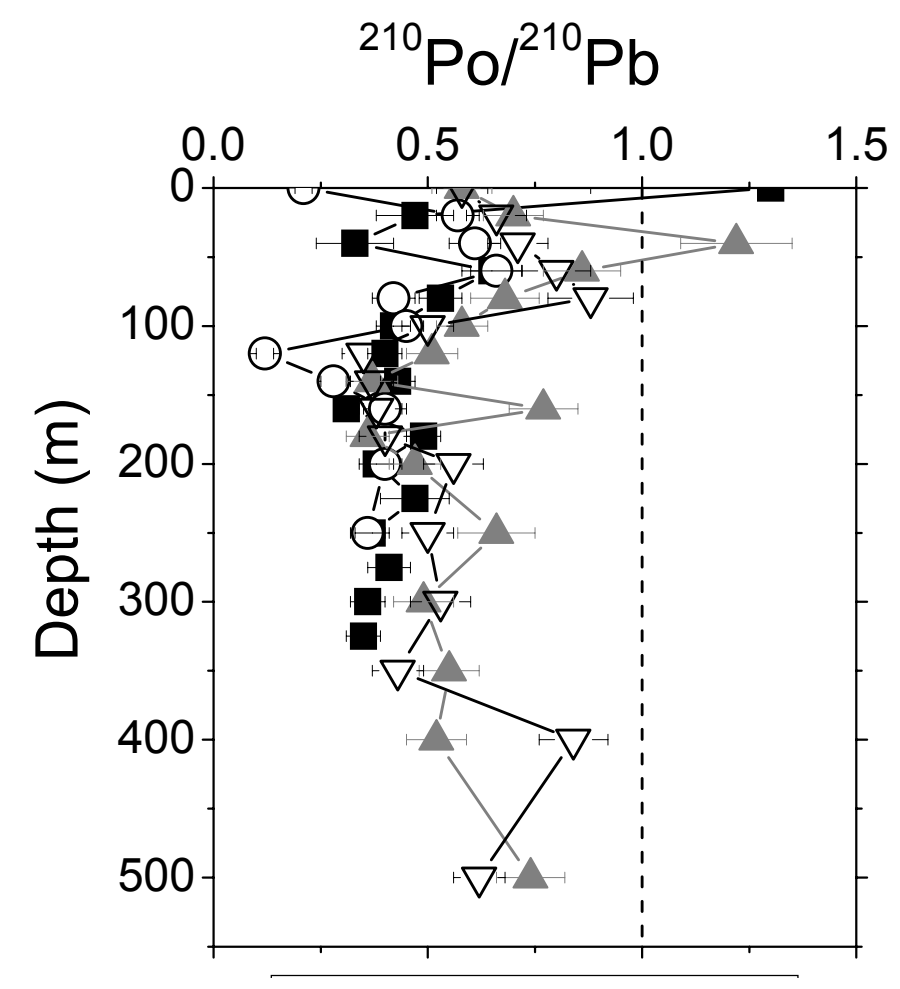


Figure 11. Buesseler et al. DSRII

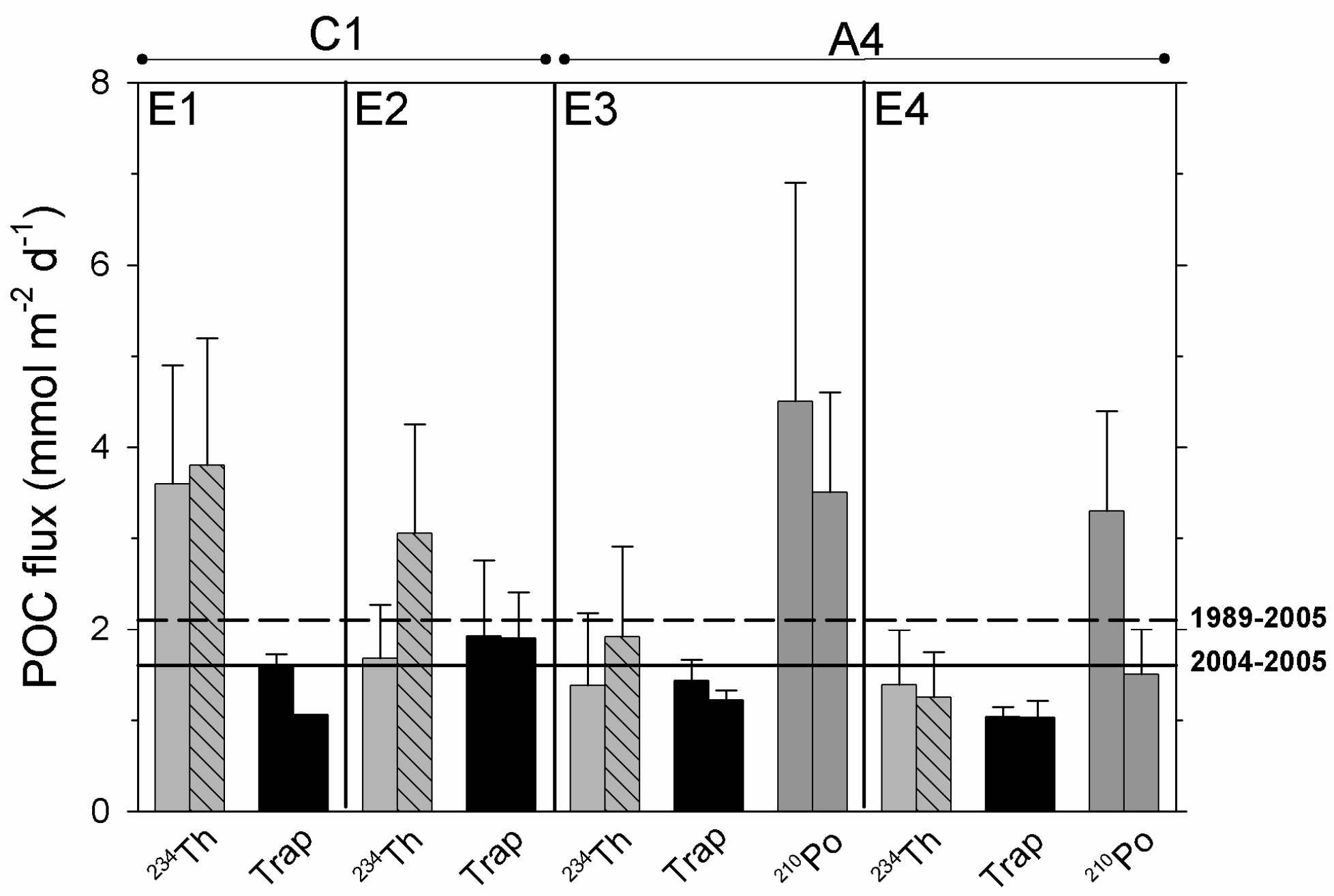

